\title{
Dynamical and Synoptic Characteristics of Heavy Rainfall Episodes in Southern Brazil
}

\author{
Mateus da Silva Teixeira \\ Instituto Nacional de Pesquisas Espaciais, São José dos Campos, São Paulo, Brazil \\ PRAKKi SATyamurty \\ Centro de Previsão de Tempo e Estudos Climáticos/INPE, São José dos Campos, São Paulo, Brazil
}

(Manuscript received 21 December 2005, in final form 19 May 2006)

\begin{abstract}
The dynamical and synoptic characteristics that distinguish heavy rainfall episodes from nonheavy rainfall episodes in southern Brazil are discussed. A heavy rainfall episode is defined here as one in which the $50 \mathrm{~mm} \mathrm{day}{ }^{-1}$ isohyet encloses an area of not less than $10000 \mathrm{~km}^{2}$ in the domain of southern Brazil. One hundred and seventy such events are identified in the 11-yr period of 1991-2001. The mean flow patterns in the period of 1-3 days preceding the episodes show some striking synoptic-scale features that may be considered forerunners of these episodes: (i) a deepening midtropospheric trough in the eastern South Pacific approaches the continent 3 days before, (ii) a surface low pressure center forms in northern Argentina 1 day before, (iii) a northerly low-level jet develops over Paraguay 2 days before, and (iv) a strong moisture flux convergence over southern Brazil becomes prominent 1 day before the episode. A parameter called rainfall quantity, defined as the product of the area enclosed by the $50 \mathrm{~mm}$ day $^{-1}$ isohyet and the average rainfall intensity, is correlated with fields of atmospheric variables such as 500 -hPa geopotential and 850-hPa meridional winds. Significant lag correlations show that the anomalies of some atmospheric variables could be viewed as precursors of heavy rainfall in southern Brazil that can be explored for use in improving the forecasts.
\end{abstract}

\section{Introduction}

Although the monthly distribution of rainfall in southern Brazil is quite uniform (Rao and Hada 1990), day-to-day variability is high. The sources for rainfall in this region are mainly cold fronts and mesoscale convective complexes (MCC; Velasco and Fritsch 1987), The extratropical cyclones approaching South America. from the west move to east-southeast after crossing the Andes while the associated cold fronts move to northnortheast, producing convective activity in southern Brazil and farther north (Kousky and Cavalcanti 1984).

MCC develop over Paraguay and northern Argentina preferentially in the spring season [SeptemberNovember (SON)]. They form during early morning hours and have a life cycle of less than 1 day (Velasco and Fritsch 1987). Interactions between low-level jet

Corresponding author address: Mateus da Silva Teixeira, INPE, Av. Astronautas, 1758, CEP 12227-010 São José dos Campos, SP, Brazil.

E-mail: mateus@cptec.inpe.br east of the Andes and the upper-level jet provide the instability for triggering the explosive development of the MCC in a moist atmosphere (Uccellini and Johnson 1979). MCC move eastward from their source region reaching Uruguay and southern Brazil, often causing heavy rainfall. Other possible synoptic-scale systems responsible for heavy rainfall are the comma-cloud systems in the Atlantic (Bonatti and Rao 1987) and the midtropospheric cut-off lows approaching from the $\mathrm{Pa}$ cific (Ramírez et al. 2000).

Occasionally, the rainfall exceeds $100 \mathrm{~mm}_{\text {day }}{ }^{-1}$ in some episodes, causing serious problems to this region. The major economic activity of the region is agriculture, and heavy rainfall may destroy entire crops over millions of hectares. The natural disasters associated with these episodes are the worst natural disasters of southern Brazil. For example, for the period between January 2000 and March 2006, these disasters, as reported by Civil Defense Department of Paraná state (information available online at http://www.defesacivil. pr.gov.br/defesacivil/eventos_naturais.php), accounted for about $65 \%$ of the total number of disasters, which 
comprise flash floods, hail, strong winds, and landslides. During some episodes the loss of livestock and human lives are also reported.

Heavy rainfall is a subjective term and its definition varies significantly. It is sometimes defined with reference to a single station's rainfall and at other times with reference to an average over a reasonably large area. However, it generally refers to a short period of time ranging from a few hours to 1 day. In many disastrously heavy rainfall episodes, both the intensity and duration of rain tend to be large. Harnack et al. (1999), for example, defined heavy rainfall episodes as those that had more than $51 \mathrm{~mm}$ of precipitation over an area of 10 $000 \mathrm{~km}^{2}$ in a period of $1-2$ days.

As mentioned above, flood is one of the most dramatic consequences of heavy rainfall episodes both in the mountainous northeastern parts and in the southwestern pampas of southern Brazil. The possibility of a specific rainfall episode causing flood at a place is a function of many factors, such as previous rainfall, regional topography, hydrological basin size, soil moisture saturation, etc. But, the rainfall itself depends on convective instability, moisture convergence, and its sustainability by synoptic-scale atmospheric conditions, which play a very important role in the maintenance of intense precipitation over sufficiently long intervals of time. Thus, the hypothesis we make here is that the small-scale and mesoscale disturbances, which produce heavy rainfall over southern Brazil, develop when there are favorable synoptic-scale situations over South America and the adjoining seas.

The objective of this study is to establish the characteristics of the synoptic-scale patterns in the middle and lower troposphere associated with heavy rainfall episodes in southern Brazil within the period of 3 days prior to the occurrence of the episodes. In addition, the amount of precipitation is correlated with selected meteorological variables to quantify the relationships between them.

Section 2 describes the datasets and methodology used, section 3 discusses the composite fields of meteorological variables, and section 4 presents the correlation fields between rainfall amounts and meteorological variables. Some dominant dynamic and synoptic features of the most intense episodes are shown in section 5 . A case study is presented in section 6 . Finally, a discussion of the results and conclusions are given in section 7 .

\section{Data and methodology}

\section{a. Datasets}

Daily precipitation data for the 11-yr period of 19912001 obtained from the Agência Nacional das Águas

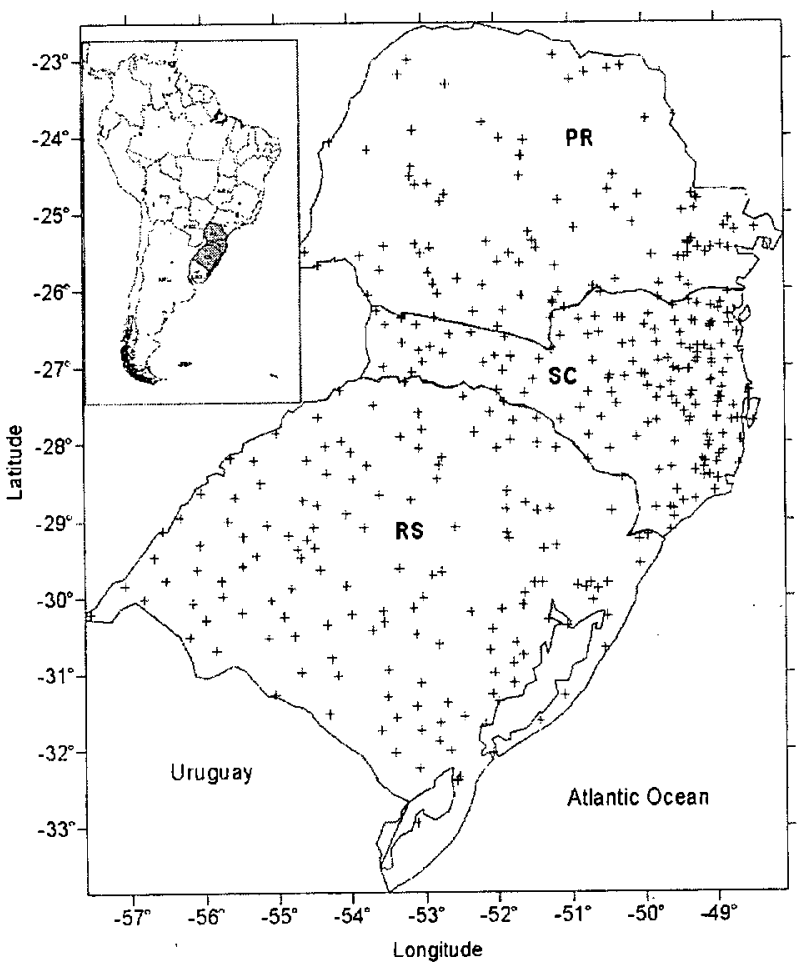

FIG. 1. Rain gauge network in southern Brazil. RS: Rio Grande do Sul, SC: Santa Catarina, PR: Paraná, and their position within the South American continent (inset).

(ANA; National Water Agency), Brazil, and available at the Centro de Previsão de Tempo e Estudos Climáticos (CPTEC; Center for Weather Forecasts and Climate Studies) are used. The rain gauge network consists of 401 meteorological stations distributed as shown in Fig. 1. As can be seen from this figure, the average density of the network is about 20 per $10000 \mathrm{~km}^{2}$. varying somewhat from one subregion to another.

The rainfall data are examined for spatial consistency and coding errors. Whenever a rainfall value greater than $50 \mathrm{~mm} \mathrm{day}{ }^{-1}$ is reported at a station (say, S1), precipitation at the stations in its immediate neighborhood (the eight nearest stations, one each in the $45^{\circ}$ sectors around S1) is examined. If less than two stations in the neighborhood report rainfall of any value the data at $\mathrm{S} 1$ are not considered for rainfall analysis. Similarly, if a station (say, S2) reports rainfall greater than $100 \mathrm{~mm} \mathrm{day}^{-1}$, the requirement is that there must be at least four stations reporting rainfall in the immediate neighborhood there of and the average rainfall in the neighboring stations must be greater than $25 \%$ of the reported rainfall at $\mathbf{S 2}$. Rainfall reports of unusually large values, which are not supported by the stations in the neighborhood, were excluded from the data sample. Such cases occurred three times in the whole 11-yr pe- 
riod when the neighborhood stations did not support rainfall reports greater than $400 \mathrm{~mm}$ day $^{-1}$. Moreover, the Geostationary Operational Environmental Satellite (GOES) cloud pictures available at the CPTEC are examined for the presence of strong convective systems supporting the rainfall. These precautions are necessary to avoid inclusion of spurious or erroneous cases of very heavy rain.

Daily 1200 UTC gridded meteorological data are obtained from National Centers for Environmental Prediction-National Center for Atmospheric Research (NCEP-NCAR) reanalysis (Kalnay et al. 1996) from their Web site. The meteorological variables used are the zonal and meridional wind components at 250,700, and $850 \mathrm{hPa}$, and at the surface ( $\mathrm{u} 250, \mathrm{v} 250, \mathrm{u} 700, \mathrm{v} 700$, u850, v850, $u$, and $v$, respectively); 500-hPa geopotential height (Z500); specific humidity at 850 and $700 \mathrm{hPa}$ (q700 and q850); air temperature at 850 -hPa and at the surface (T850 and $T$ ); sea level pressure (SLP); precipitable water (PW); and the lifted index (LI). The data have a spatial resolution of $2.5^{\circ}$ latitude $\times 2.5^{\circ}$ longitude. The 1200 UTC datasets are chosen because of the greater density of observations over the South American continent at this time of the day, and therefore the analysis is expected to be more accurate.

\section{b. Heavy rainfall episodes and their seasonal and geographical distribution}

The definition of heavy rainfall varies from study to study depending on their objectives (Zhu and Thot 2001 ) and the availability and density of rainfall data. Some studies used only a precipitation threshold and duration to select their episodes. Konrad (1997), in his study of flash floods over the plains of the United States, selected all rainfall episodes that presented precipitation greater than or equal to $50 \mathrm{~mm}$ in $6 \mathrm{~h}$. Carvalho et al. (2002) defined extreme rainfall episodes as those in which the precipitation in $24 \mathrm{~h}$ is greater than $20 \%$ of the seasonal climatological total precipitation for one station. Other studies used additional conditions to select heavy rainfall episodes. Junker et al. (1999) selected episodes based on the size of the $75-\mathrm{mm}$ isohyet. Whenever the area enclosed by the $75-\mathrm{mm}$ isohyet is equal to or greater than $17000 \mathrm{~km}^{2}$ it is considered as a heavy rainfall episode. Harnack et al. (1999) considered all episodes that presented precipitation above $51 \mathrm{~mm}$ ' in an area greater than or equal to 10000 $\mathrm{km}^{2}$ (represented by four contiguous grid points), in 1 or 2 days, as heavy rainfall episodes.

The major concern of the present study is with the synoptic-scale features associated with heavy rainfall episodes, so an adequate definition should discard intense local rainfall episodes caused by isolated small-

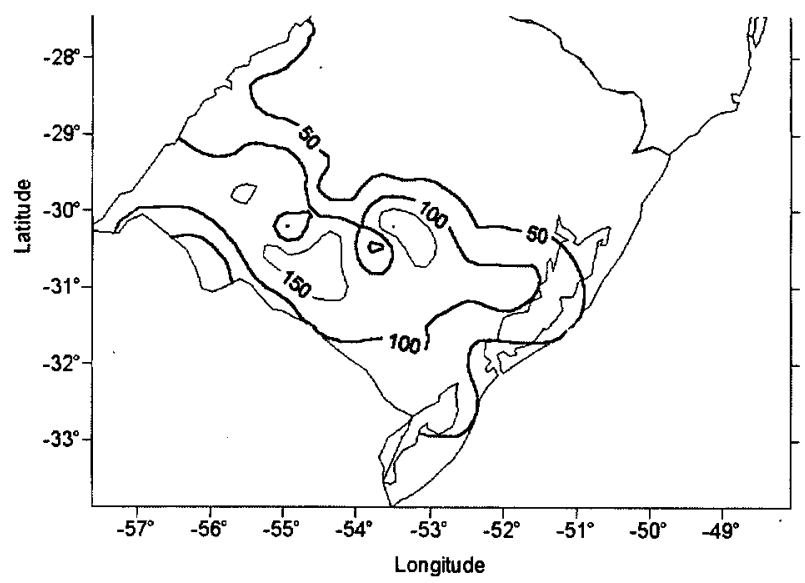

FIG. 2. Isohyet analysis of a heavy rainfall episode between 11 and 12 Apr 1992 in southern Brazil. Contour interval is $50 \mathrm{~mm}$.

scale atmospheric perturbations. Following previous studies mentioned above and based on the rain gauge network of southern Brazil, a rainfall episode is classified as heavy when it presents a minimum area of 10 $000 \mathrm{~km}^{2}$ of the $50-\mathrm{mm}$ (A50) isohyet in $24 \mathrm{~h}$ in the domain of southern Brazil (shown in Fig. 1). The isohyet analysis of a heavy rainfall episode (the case study of which is presented in section 6) is shown in Fig. 2 . Between 11 and 12 April 1992 there was heavy and widespread rainfall over the southern portions of the state of Rio Grande do Sul (RS in Fig. 1). The rainfall exceeded $50 \mathrm{~mm}^{-1 a y}{ }^{-1}$ over a large area, and even the $100 \mathrm{~mm} \mathrm{day}^{-1}$ isohyet occupied an area larger than $10000 \mathrm{~km}^{2}$.

If a heavy rainfall episode persists for more than 1 day in the domain, only the first day is considered, even if the system intensifies later. That is, the present study is interested in the atmospheric conditions associated with the beginning of a heavy rainfall episode and not with its persistence or subsequent intensification. This procedure assures that only nonsequential days will be considered as separate episodes. Because one purpose of this study is to show the difference between heavy rainfall episodes and nonheavy rainfall episodes, the latter should also be defined. A nonheavy rainy episode is one in which rainfall is reported from at least two stations and A50 is less than $10000 \mathrm{~km}^{2}$. In these cases, also only nonsequential rainfall days are considered.

In the 11-yr period of 1991-2001, 170 rainfall episodes are classified as heavy. A monthly distribution of both these episodes and the nonheavy ones is shown in Fig. 3. As can be seen, the nonheavy and heavy rainfall episodes are well distributed over the year. About $25 \%$ of the nonconsecutive rainy days are categorized as heavy. 


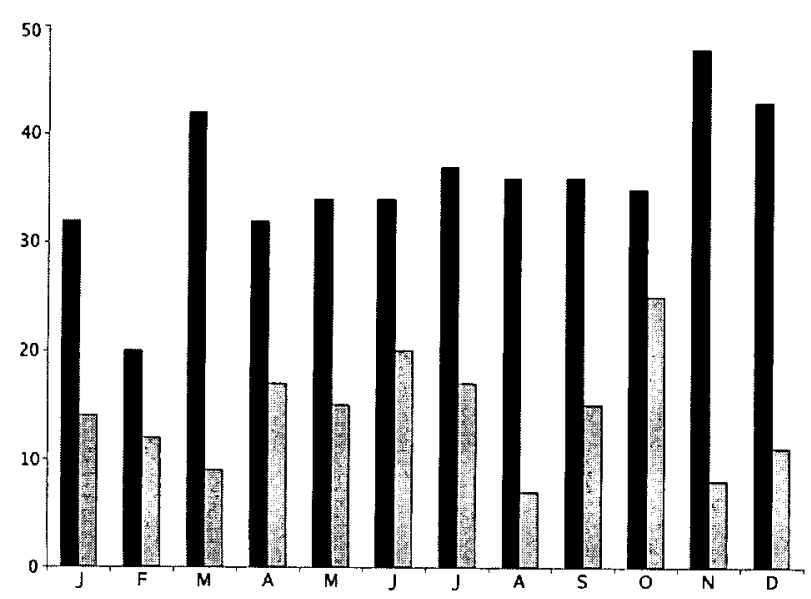

FIG. 3. Monthly distribution of the heavy rainfall episodes (gray) and nonheavy rainfall episodes (dark) in southern Brazil in the period of 1991-2001.

For the 170 heavy rainfall episodes the areas enclosed by 50 and $100 \mathrm{~mm} \mathrm{day}^{-1}$ isohyets (A50 and A100, respectively) are calculated. The area-averaged rainfall within the $50 \mathrm{~mm} \mathrm{day}{ }^{-1}$ isohyet (R50) is also obtained by taking a simple mean of all the valid rainfall reports within that area in the domain of southern Brazil. A frequency distribution of A50 for the 170 heavy rainfall episodes separated into the four seasons of the year is presented in Fig. 4. It can be seen that a large majority of the episodes (70\%) have $80000 \mathrm{~km}^{2} \geq$ A50 $\geq 15000 \mathrm{~km}^{2}$. The mean areal coverage of the heavy rainfall episodes considered in this study is about $65000 \mathrm{~km}^{2}$, which means that the chosen episodes are fairly extensive.

Figure 5 presents the positions of the central points of A50 for the 170 episodes, and it can be seen that the heavy rainfall episodes in southern Brazil do not have a preferred location in any given season. In this sense, the southern Brazil region is fairly homogeneous in terms of heavy rainfall episodes. The only preferred coastal area is located in the SC state in summer [DecemberFebruary (DJF)].

\section{c. Composite charts}

To analyze the dynamical and synoptic features associated with the heavy rainfall episodes, composites of the atmospheric variables mentioned in section $2 \mathrm{a}$ are calculated for the day of the episode and up to 3 days prior. The composites are prepared for each season, thus permitting the examination of seasonal differences, if any, of the heavy rainfall episodes.

Composite fields are constructed in the spatial domain of $10^{\circ}-60^{\circ} \mathrm{S}, 120^{\circ}-20^{\circ} \mathrm{W}$ for $\mathrm{Z} 500$, and in the $10^{\circ}-$ $60^{\circ} \mathrm{S}, 80^{\circ}-30^{\circ} \mathrm{W}$ domain for the others variables. The

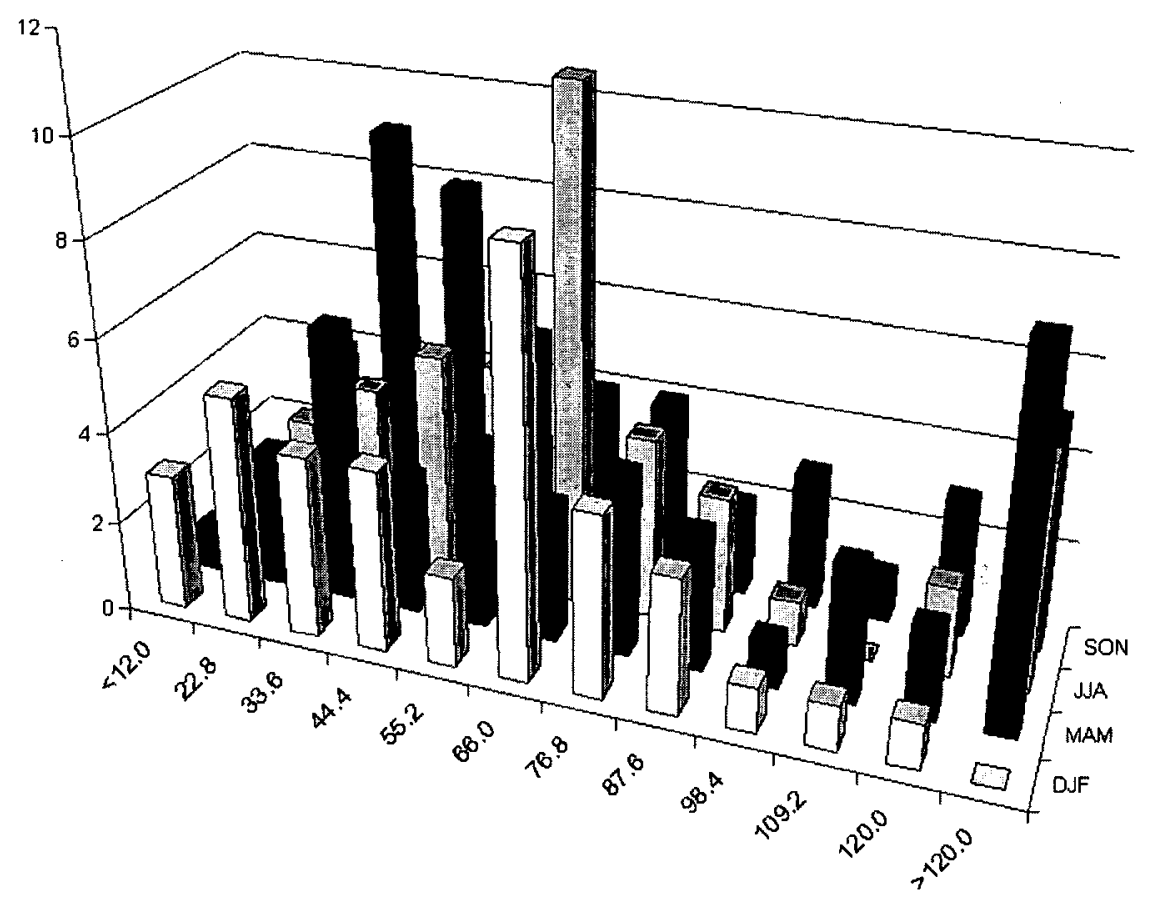

FIG. 4. Frequency distribution of heavy rainfall episodes in southern Brazil based on area enclosed by the $50 \mathrm{~mm}$ day $^{-1}$ isohye1 (A50) in the period of 1991-2001 for each season. Horizontal axes show seasons and $\mathrm{A} 50$ in $10^{3} \mathrm{~km}^{2}$, and the vertical axis shows frequency. 


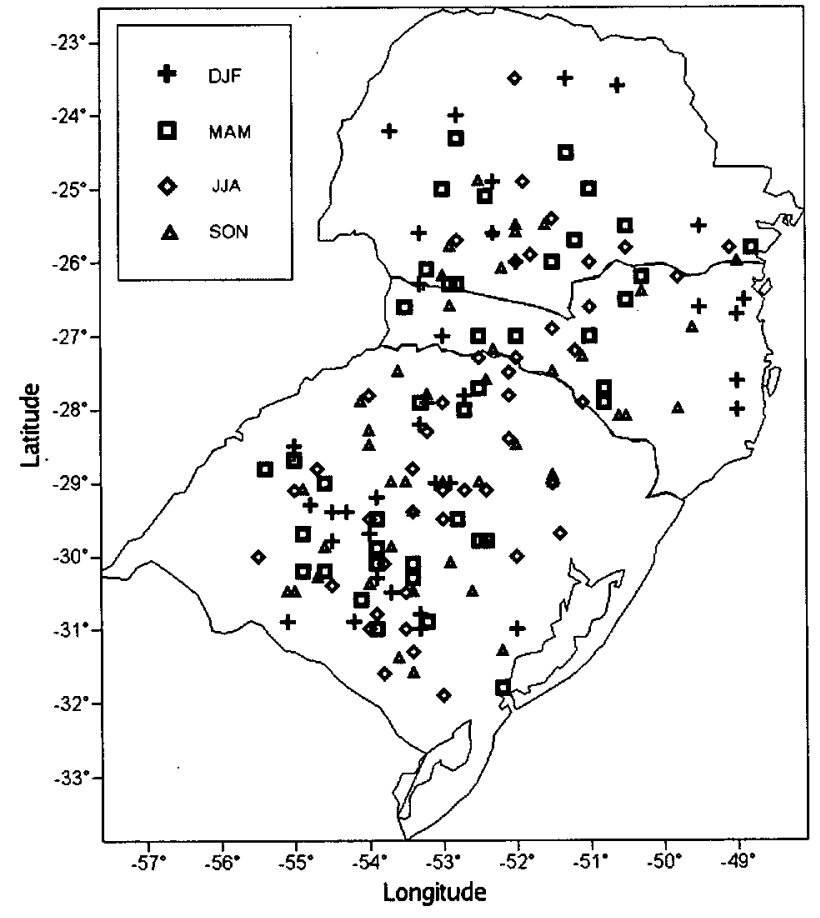

FIG. 5. Geographical distribution of the centroids of A50 for the 170 heavy rainfall episodes in southern Brazil. Different symbols (shown in the inset) represent different seasons.

composites are obtained for the four seasons-winter [June-August (JJA)], spring (SON), summer (DJF), and autumn [March-May (MAM)]-separately by taking an average of all observed episodes in each of those seasons, for lags of $0,1,2$, and 3 days. Lag 0 corresponds to the starting day of the rainy episode. The sequences of composites are useful for tracking the evolution of the synoptic-scale systems responsible for the heavy rainfall episodes in southern Brazil. To understand which synoptic-scale ingredients make the difference between a heavy rainfall episode and a nonheavy rainfall episode the difference between the heavy rainfall composites with respect to the nonheavy rainfall composites are obtained. These difference fields can provide useful information for the operational meteorologists for forecasting activities.

\section{d. Rainfall quantity and rank correlation}

To relate the rainfall recorded during the episodes with the atmospheric patterns, a simple rainfall parameter is considered. Because both the areal extent and the intensity of rainfall are used to select heavy rainfall episodes, a parameter involving both the features of rainfall is a better choice to obtain insights into the relationship between atmospheric variables and rainfall. Thus, a parameter called rainfall quantity (RQ) is defined as the product of the area enclosed by the 50 $\mathrm{mm}$ day $^{-1}$ isohyet and the mean rainfall within this area in the domain of southern Brazil.

The correlations between $\mathrm{RQ}$ and the atmospheric parameters are calculated using the rank correlation. This choice is made because the Pearson correlation assumes that samples are in normal distribution, which is rarely true for precipitation data (Wilks 1995). To avoid data transformation into normal distribution we use the rank correlation coefficient that uses rank information of the samples instead of the real data. The "new" samples are in normal distribution. The RQ is correlated with all the atmospheric variables defined in section 2a at all of the grid points over the domain.

As with composites, correlation fields are calculated for each season and up to 3 days prior to the heavy rainfall episode. The time evolution of correlation fields permits investigation of how and when a meteorological variable starts becoming important. By "becoming important", we mean that the variable presents a significant relationship with rainfall. It is reasonable to believe that the sooner the variable becomes important (up to 3 days prior the beginning of the episode), the higher the potential for this variable to be used in forecasting activity. Both correlation and composite fields are tested for statistical significance using a Student's $t$ test at the $95 \%$ confidence!level.

\section{Mean characteristics associated with heavy rainfall episodes}

The seasonal distribution of heavy rainfall episodes in the 11-yr period is shown in Table 1 . The episodes are almost uniformly distributed over the year, with the autumn season having the largest mean RQ value. Therefore, for the sake of brevity, the composites for the autumn season are presented in more detail and the other seasons are mentioned wherever there is a noticeable difference from the autumn case.

\section{a. 500-hPa geopotential difference fields}

The 500-hPa geopotential difference fields between the 41 heavy rainfall episodes and the 107 nonheavy rainfall episodes, along with the composite fields for the heavy rainfall episodes for the autumn season are shown in Fig. 6. On D - 2, two days before the day of heavy rainfall occurrence, a significant negative difference of $30 \mathrm{~m}$ over southwestern South America indicates the beginning of the deepening of a midtropospheric trough, as can be seen in the composite field. On $\mathrm{D}-1$, the difference deepens to $60 \mathrm{~m}$ as it moves 
TABLE 1. Seasonal distribution of the heavy rainfall episodes in southern Brazil and mean values for the parameters presented in methodology: A100 and A50 are the areas enclosed by the isohyets of 100 and $50 \mathrm{~mm}^{-1} \mathrm{dy}^{-1}$, respectively; R50 is the average rainfall in $\mathrm{A} 50$.

\begin{tabular}{lccccc}
\hline \hline Season & Frequency & $\mathrm{A} 50\left(10^{4} \mathrm{~km}^{2}\right)$ & $\mathrm{A} 100\left(10^{4} \mathrm{~km}^{2}\right)$ & $\mathrm{R} 50\left(\mathrm{~mm} \mathrm{day}{ }^{-1}\right)$ & $\mathrm{RQ}_{\left(10^{4} \mathrm{~km}^{2} \times \mathrm{mm} \mathrm{day}^{-1}\right)}$ \\
\hline Summer & 37 & 5.0 & 0.3 & 78 & 396.3 \\
Autumn & 41 & 7.4 & 0.6 & 77 & 581.4 \\
Winter & 44 & 5.3 & 0.5 & 72 & 395.8 \\
Spring & 48 & 5.0 & 0.3 & 72 & 469.8 \\
\hline
\end{tabular}

into Argentina. On the day of heavy rainfall occurrence (D0), the largest difference region is over central Argentina. The sequence shows the intensification of the trough and its eastward movement at a speed of $4^{\circ}$ longitude per day. The difference intensifies from $D-$ 3 to $\mathrm{D}-1$ and accompanies the trough movement.

Because these differences are constructed with respect to the rainy days that are not classified as heavy episodes, the above-described behavior obviously constitutes an ingredient that makes the difference. Thus, the heavy rainfall episodes in southern Brazil, on aver- age, are associated with 60-m-deeper troughs than those associated with nonheavy rainfall episodes, which are only $30 \mathrm{~m}$ deeper than the climatology (fields not shown).

\section{b. Sea level pressure difference fields}

The sea level pressure composites and differences for the autumn season are shown in Fig. 7. On the D - 2 day, a negative difference area can be seen in southern Chile and Argentina. In the following days, this differ-
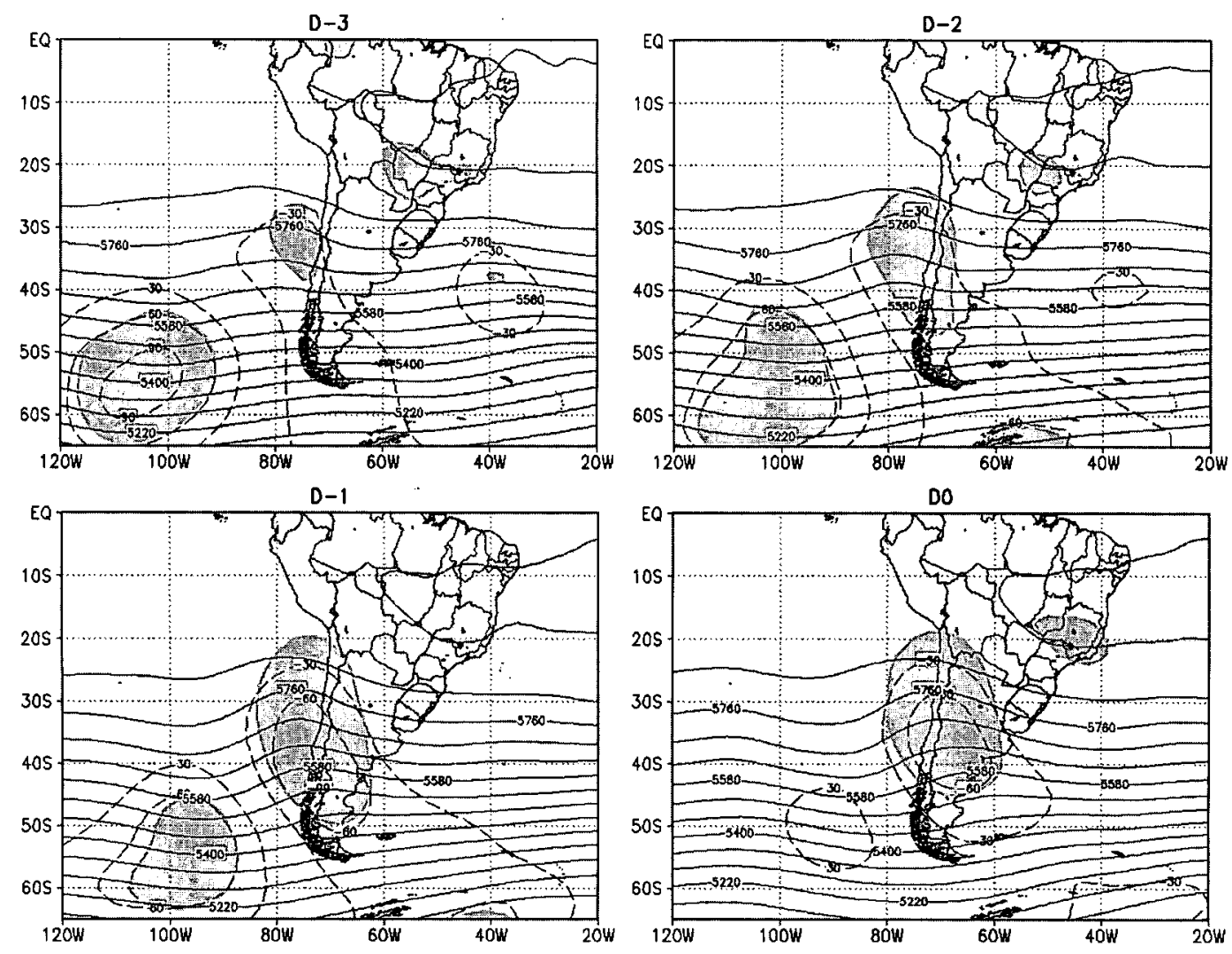

FiG. 6. 500-hPa geopotential height (ì) composites (continuous lines) and difference fields (dashed lines) for 41 heavy rainfall episodes in MAM in southern Brazil. D $-d$ above each panel refers to the $d$ th day prior to the heavy rainfall episode. Contour interval of dashed lines is $30 \mathrm{~m}$. Contour interval of continuous lines is $60 \mathrm{~m}$. Shaded areas are significant at $95 \%$ level. 

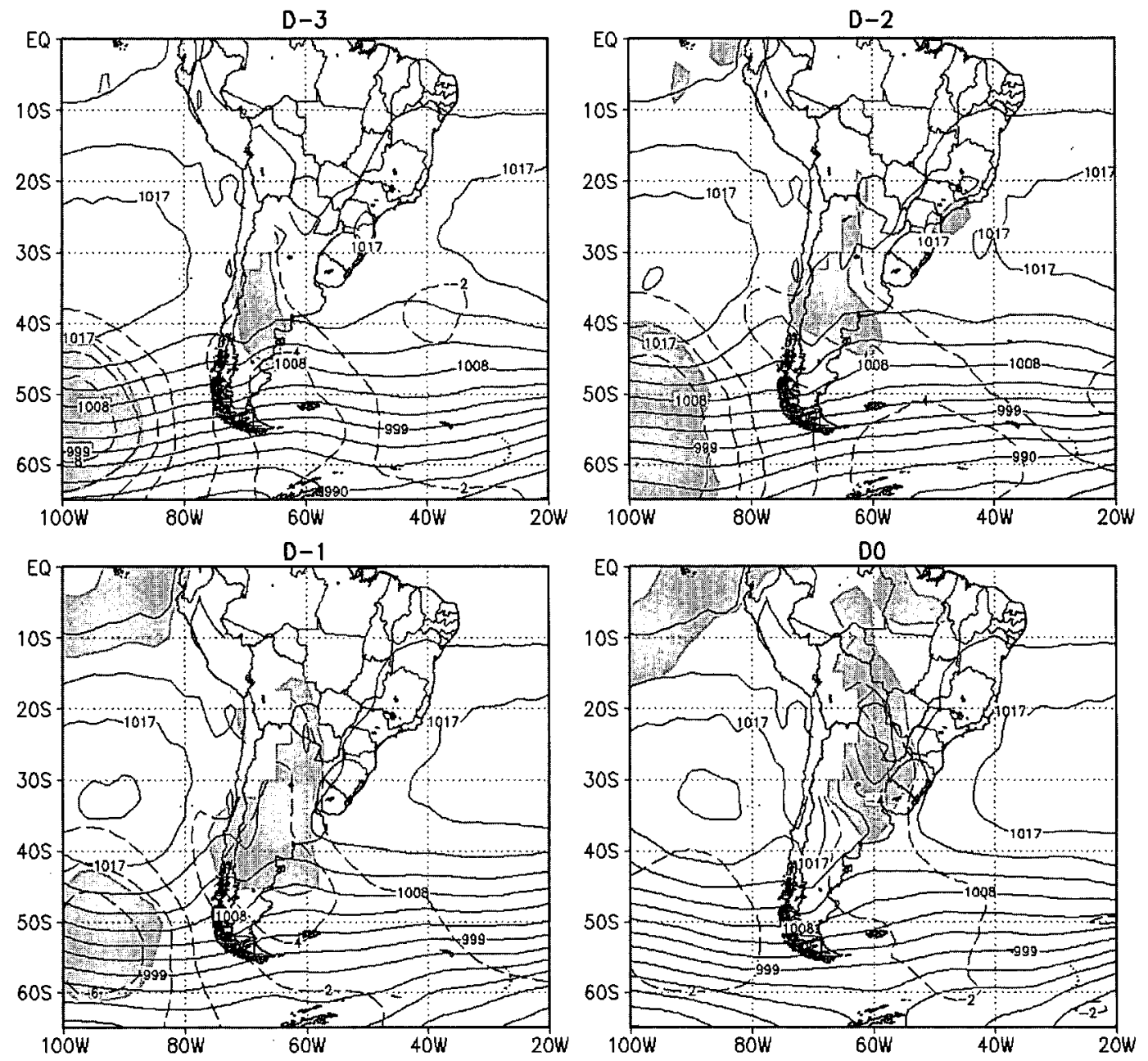

FIG. 7. Sea level pressure composites (continuous lines) and difference (dashed lines) between heavy rainfall composites and nonheavy rainfall composites for D -3 to D0. The Andes region is masked out. Contour interval is $3 \mathrm{hPa}$ for surface pressure and $2 \mathrm{hPa}$ for difference. Shaded areas are significant at $95 \%$ level.

ence strengthens and moves northward to central parts of the continent. From D -1 to D0 this deepens from a difference of -2 to $-4 \mathrm{hPa}$ over Paraguay and northern Argentina. On D0, a low pressure center forms east of the Andes in northern Argentina and Paraguay. Such a low is known as the Chaco low (Saulo et al. 2004) and is often observed in summer. The low pressure difference shown in Fig. 7 is significant on D -1 and D0. The surface low development has the dynamical forcing of the midtropospheric cyclonic vorticity advection associated with the trough movement observed in Fig. 6. The sea level pressure composites show that a stronger-than-normal west-to-east pressure gradient builds up east of the surface low center. This situation supports stronger-than-normal surface northerlies (as shown in the next subsection) from south of the Amazon forest to southern Brazil.

\section{c. 850-hPa meridional wind component, moisture flux convergence, and thermal advection difference fields}

The lower-tropospheric winds over central parts of South America are predominantly north-northwesterlies in the autumn season (Satyamurty et al. 1998). The vertical profiles of wind often show a belt of a maximum north-northwesterly component with magnitude greater than $12 \mathrm{~m} \mathrm{~s}^{-1}$ around $850 \mathrm{hPa}$ that has a sufficiently narrow zonal extent, with enough vertical shear to constitute a low-level jet (Marengo et al. 2004). The jet transports water vapor southward from the humid Amazon forest. The moisture flux convergence (MFC) over southern Brazil is an important factor for the rainfall there.

The composites for a meridional wind component 

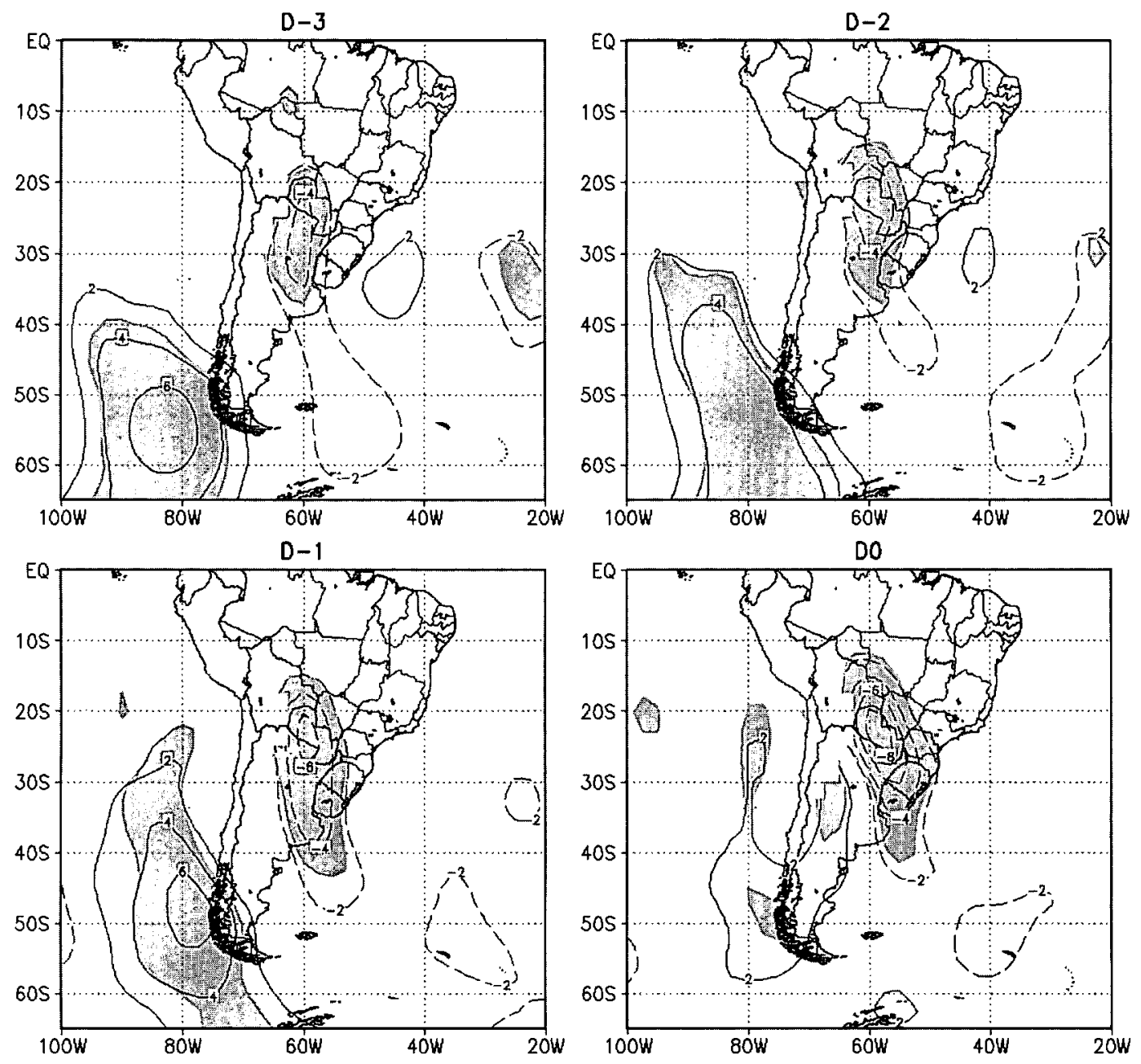

FiG. 8. 850-hPa meridional wind component difference $\left(\mathrm{m} \mathrm{s}^{-1}\right)$ between heavy and nonheavy rainfall composites for D -3 to D0 for MAM. Contour interval is $2 \mathrm{~m} \mathrm{~s}^{-1}$. Shaded areas are significant at $95 \%$ level.

difference at $850 \mathrm{hPa}$ are shown in Fig. 8 . It can be seen that since day $\mathrm{D}-3$ a significant narrow area with northerly wind difference is located over Paraguay and adjacent areas. This persists during days $D-2$ and $\mathrm{D}-1$, gaining strength gradually. The northerly anomaly on D0 has an intensity of more than $8 \mathrm{~m} \mathrm{~s}^{-1}$ over Paraguay and western sections of southern Brazil, consistent with the deepening of the surface low pressure (Fig. 7). The winds in the composites for heavy rainfall episodes (not shown) are north-northwesterly and have magnitudes greater than $12 \mathrm{~m} \mathrm{~s}^{-1}$.

As a consequence of the stronger meridional winds, stronger moisture transport from the north over Paraguay, Bolivia, and southwestern Brazil can be seen since D - 3 (Fig. 9). The MFC difference is strong over Bolivia, Paraguay, and northern Argentina since D - 3 . The MFC strengthens on D -2 and the whole region of strong convergence moves east-southeastward, increas- ing in strength between days $D-2$ and $D-1$. The convergence area further increases both in size and strength on the day of the heavy rainfall episode (D0), covering almost the entire southern Brazil region and the northeastern parts of Argentina. The order of magnitude of moisture convergence over southern Brazil is about $10^{-6} \mathrm{~s}^{-1}$. As can be seen, this area of strong MFC is mainly due to moisture transport (arrows) coming from the Amazon region and, to some extent, from the southeast Brazil-Atlantic Ocean regions.

Strong northerly winds bring not only moisture but also warm air into southern Brazil, contributing to even greater enhancement of the conditions for convective development. As can be seen from Fig. 10, on D - 3 a warm advection difference region is located over northern Argentina and Uruguay west of southern Brazil. This area broadens from $D-2$ to $D-1$, and gets stronger between days $\mathrm{D}-1$ and $\mathrm{D} 0$. The difference in 

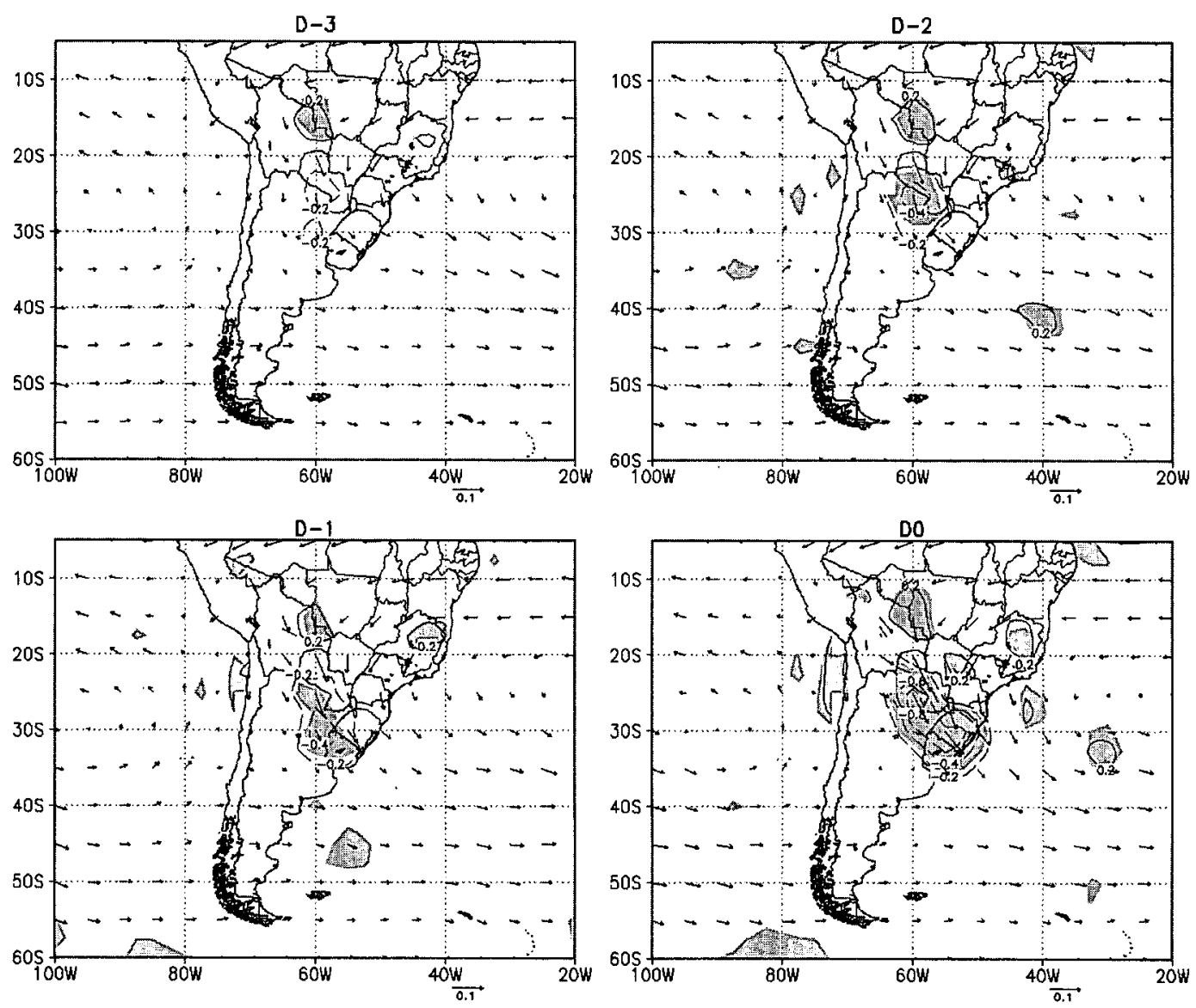

FiG. 9. 850-hPa MFC differences $\left(10^{-7} \mathrm{~s}^{-1}\right)$ (contours) and moisture transport differences $\left(10^{-2} \mathrm{~kg} \mathrm{~m} \mathrm{~kg}^{-1} \mathrm{~s}^{-1}\right)$ (vectors) between heavy and nonheavy rainfall composites for $\mathrm{D}-3$ to DO for autumn. Contour interval is $0.2 \times 10^{-7} \mathrm{~s}^{-1}$.

warm advection between the heavy rainfall episodes and the nonheavy ones on D0 is of the order of $5 \mathrm{~K}$ day ${ }^{-1}$. The upward motion necessary to partially compensate for the warm advection, by adiabatic cooling, has to be strong, and thus the convective activity is either more easily initiated or strengthened.

\section{d. Mass divergence difference fields at 250,700 , and $850 \mathrm{hPa}$, and at the surface}

Figure 9 presents strong evidence of the association of the large differences of MFC at $850 \mathrm{hPa}$ between heavy and nonheavy rainfall episodes. Banacos and Schultz (2005) had discussed the utility of this variable to forecast convective initiation (CI) in middle latitudes. These authors show that the contribution of moisture advection to MFC is one order magnitude smaller than the convergence term. They thus recommend that the mass convergence field should be used in the place of MFC.

The mass convergence composites at 700 and 850
$\mathrm{hPa}$, and at the surface are obtained. Their differences from nonheavy rainfall episodes are very similar to the difference in MFC at $850 \mathrm{hPa}$. At the surface and 700 $\mathrm{hPa}$, the mass convergence differences are not large (not shown). These results show that in subtropical Brazil either MFC or mass convergence obtained with $2.5^{\circ}$ resolution data at the $850-\mathrm{hPa}$ level is equally good for diagnosing fairly widespread convective activity and precipitation.

At upper-tropospheric levels $(250 \mathrm{hPa})$, the mass divergence presents significant positive differences since D - 2 (Fig. 11). The positive region west of southern Brazil widens, doubles in intensity, and moves eastward from D -2 (Fig. 11a) to D0 (Fig. 11b). This divergence compensates for the mass convergence at the lower levels for maintaining mass conservation.

\section{e. Difference fields of other diagnostics}

To obtain an as complete as possible picture of the heavy rainfall episodes in southern Brazil, the differ- 

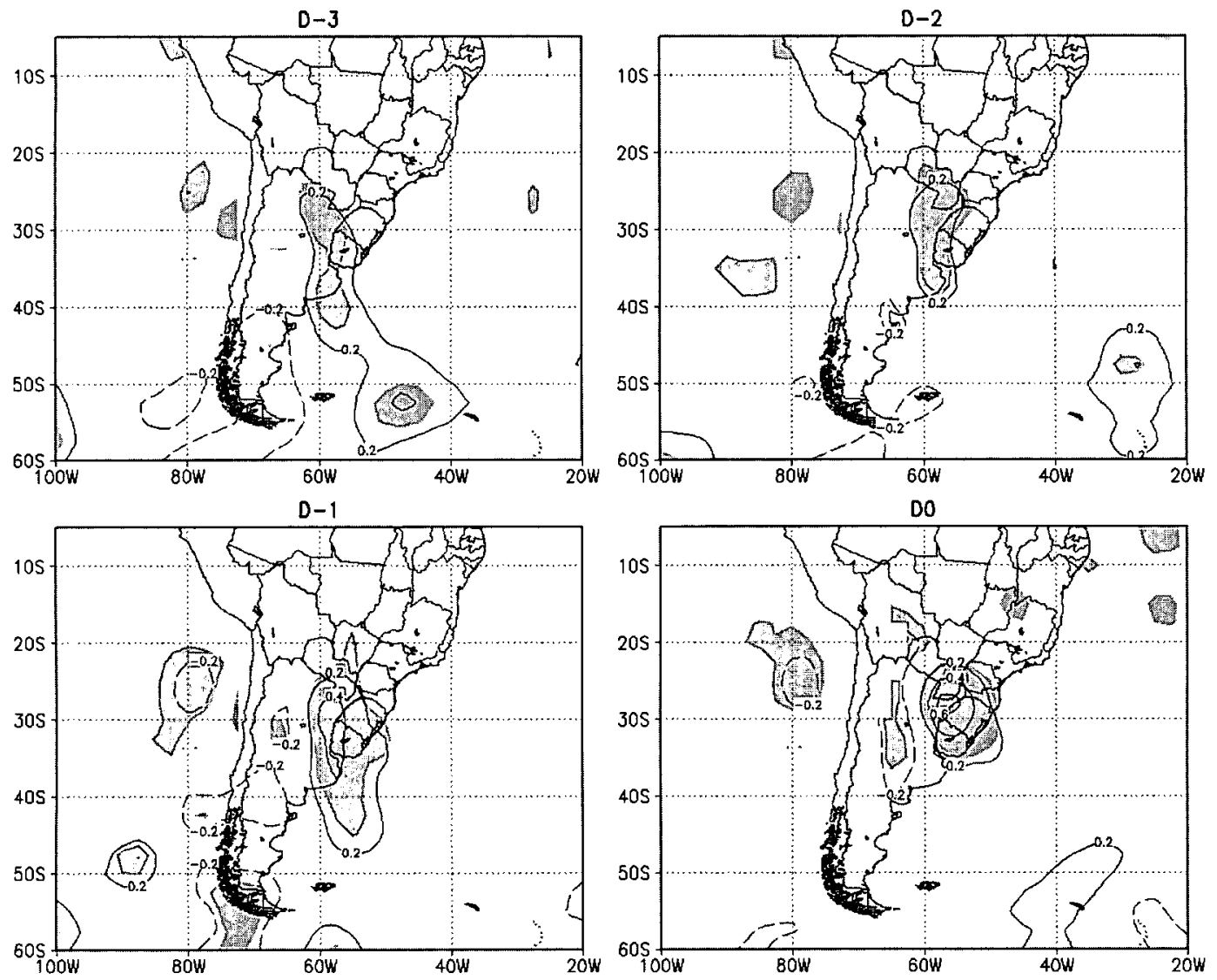

FIG. 10. Same as in Fig. 8, but for the horizontal thermal advection $\left(10^{-4} \mathrm{~K} \mathrm{~s}^{-1}\right)$ at $850 \mathrm{hPa}$. Contour interval is $0.2 \times 10^{-4} \mathrm{~K} \mathrm{~s}^{-1}$.

ence fields of three more variables, namely, surface temperature, precipitable water, and lifted index are calculated. However, these fields do not present large differences between heavy and nonheavy rainfall epi- sodes. Moreover, they presented some differences from nonheavy rainfall episodes only on day D0 (about $2 \mathrm{~kg} \mathrm{~m}^{-2}$ for precipitable water, $-2 \mathrm{~K}$ for lifted index, and less than $1 \mathrm{~K}$ for surface temperature). The differ-

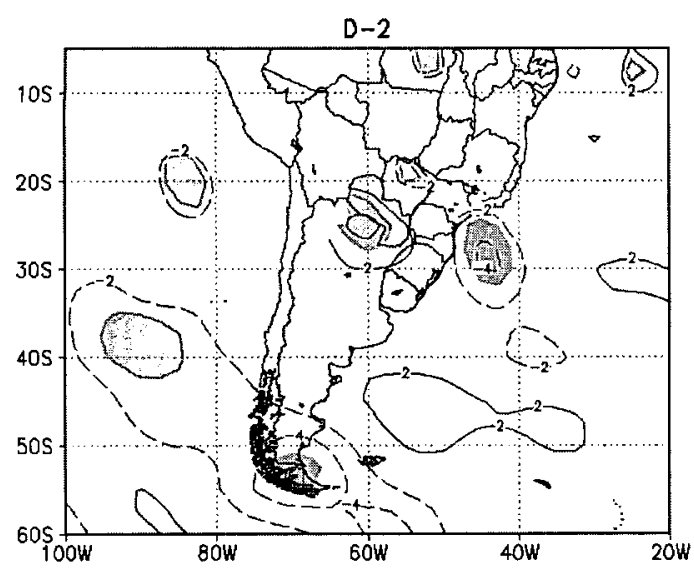

(a)

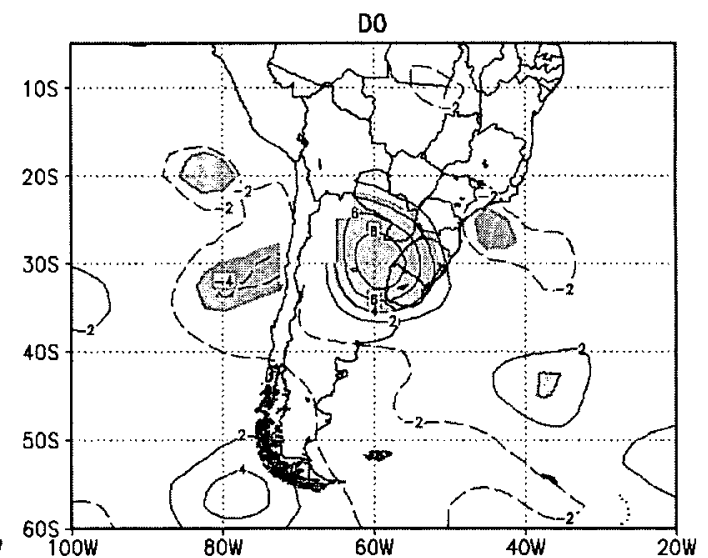

(b)

FIG. 11. Mass divergence $\left(10^{-6} \mathrm{~s}^{-1}\right)$ difference between heavy and nonheavy rainfall composites at $250 \mathrm{hPa}$ for MAM on D -2 and D0. Contour interval is $0.2 \times 10^{-6} \mathrm{~s}^{-1}$. Shaded areas are significant at $95 \%$ level. 
ences mentioned above are with the right sign to indicate an increase of the convective activity, but the magnitudes are not significant. This means that the differences in thermodynamical structure are not as important as the dynamical structure differences to tell the heavy rainfall events from the nonheavy ones.

\section{f. Interseasonal differences}

The winter differences of the geopotential height fields are the largest among all the seasons, and two times larger than in the autumn episodes. Obviously, this is due to stronger meridional gradients of $500-\mathrm{hPa}$ geopotential heights. Although a midtropospheric trough is an essential ingredient of the heavy rainfall events, its strength varies greatly from season to season, being the deepest in winter and weakest in summer. The stronger meridional gradient of the geopotential height field translates into stronger zonal upper winds south of $25^{\circ} \mathrm{S}$ in winter. Large upper-level divergence is observed ahead of the trough and south of southern Brazil (field not shown), in all days analyzed. However, this upper-level divergence is only slightly greater than in autumn. This means that the ageostrophic component of the jet is of the same order of magnitude in both winter and autumn. In winter, the meridional thermal gradients in the lower troposphere in general are stronger. However, the differences in thermal advection are not greater those than in autumn, even though the meridional wind differences between nonheavy and heavy rainfall episodes are similar to those in autumn. One reason for this is that over the central parts of South America the thermal gradient during the heavy rainfall episodes is not very strong. This is verified by the constant presence of a warm difference at the surface from D -3 up to D0 (Fig. 12a and b) west of southern Brazil. Among the other parameters only precipitable water shows large values (about $6 \mathrm{~kg} \mathrm{~m}^{-2}$ ) since D -3 (Fig. $12 \mathrm{c}$ ), south of southern Brazil, while the remaining parameters show characteristics very similar to those of the autumn season. It is interesting to note that the precipitable water in winter has the lowest values compared with the other seasons, and then that the difference between the heavy rainfall composite and this value, that is, the difference shown in Fig. 12c, is large.

For the spring season, the heavy rainfall episodes presented the largest values of MFC and mass convergence at the 700-hPa level (field not shown). (In other seasons, this variable presents values less than half of that observed at $850 \mathrm{hPa}$.) In spring, 700-hPa MFC is almost as strong as that at the 850 -hPa level. That is, the depth of the lower troposphere over which MFC operates in spring is noteworthy. Actually, the northerly jet responsible for the transport of water vapor and sensible heat to southern Brazil is deeper in spring. This is due to the greatest west-to-east pressure gradients in the middle and lower troposphere and at the surface (Fig. 13). This also contributes to the greater-thanautumn differences for thermal advection at the 850 $\mathrm{hPa}$ and surface temperatures (fields not shown). The other variables have almost the same values as in autumn.

In summer, all variables and parameters present weaker intensities and smaller differences than in autumn. Moreover, almost none of them show significant values. In particular, the lifted index parameter does not show any differences between heavy and nonheavy rainfall episodes. As will be shown in the next section, this parameter does not show a significant relationship with heavy rainfall episodes. It is interesting to note that even though the difference fields do not show large values, the absolute value of the meridional wind is the largest in summer. Moreover, the axis of the maximum winds has an orientation that is not as meridional as in the autumn and spring seasons (field not shown). An orientation from northwest to southeast is more evident. The region of MFC also changes its position in summer to the southern Brazil coast (field not shown), which is different from that in the spring and autumn seasons, and presents the convergence maximum west of southern Brazil. This perhaps explains the preferential location of the heavy rainfall episodes in summer centered over the SC coastal regions seen in Fig. 5.

Although there are seasonal differences in the magnitudes and positions of the regional synoptic features, there are some common features for the heavy rainfall episodes in southern Brazil. These features are the approach of a midtropospheric trough from $\mathrm{D}-3$ to $\mathrm{D} 0$, a formation of an area of low pressure west of southern Brazil on D0, and a strong lower-level moisture transport from the north and MFC over Paraguay moving on to southern Brazil from D - 2 to D0.

Many Brazilian weather-forecasting centers attribute relative great importance for the instability indexes (M. E. Seluchi 2006, personal communication). From the results presented above, the indexes cannot distinguish situations of heavy rainfall from the nonheavy rainfall situations. It should be clearly stated that more specific studies must be performed to evaluate the reliability of instability indexes in severe weather prediction, but the results shown here call for a greater caution in their use. So, the importance for including variables and parameters, which really present some relationship with severe weather, such as heavy rainfall, in prediction strategy cannot be overemphasized. 


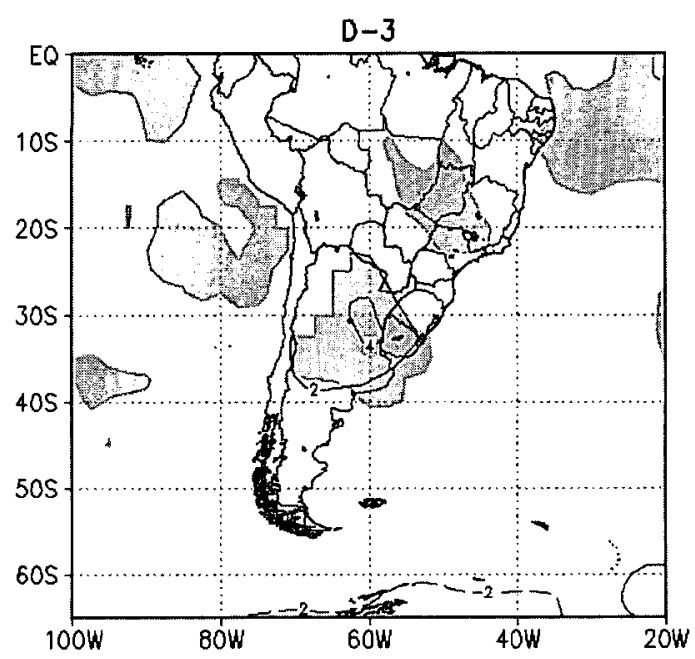

(a)

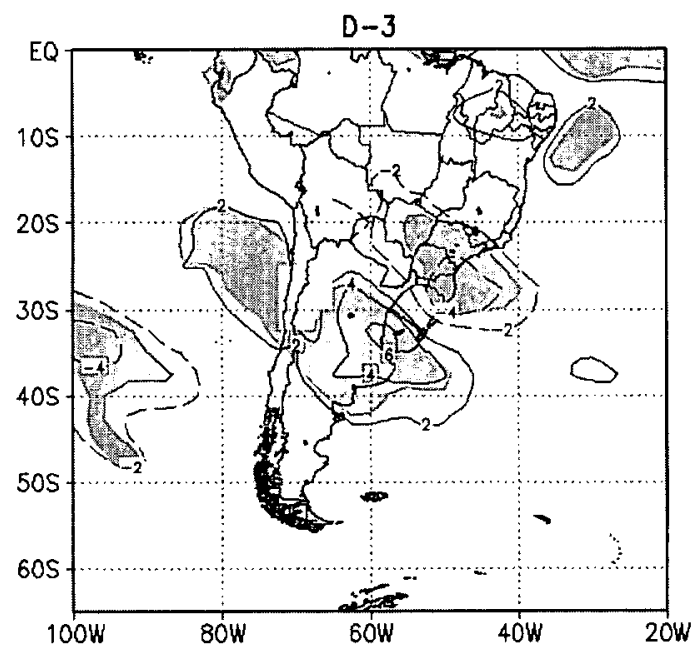

(c)

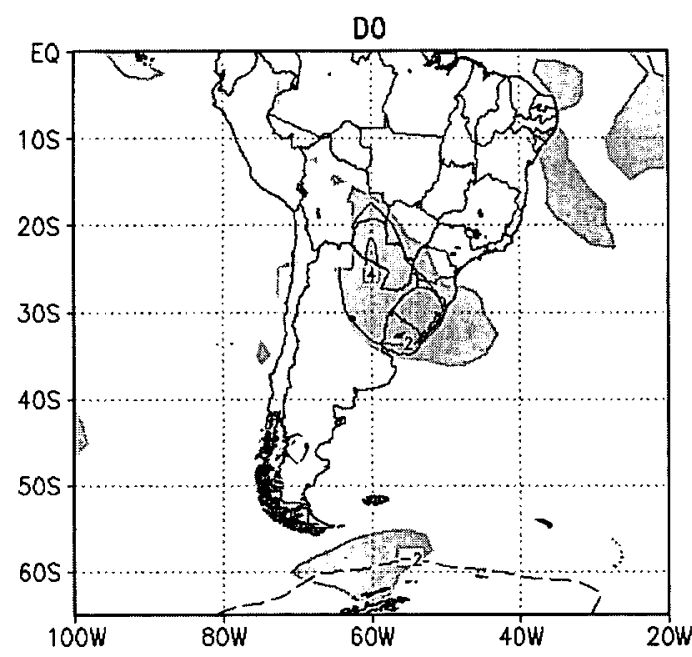

(b)

FIG. 12. Same as in Fig. 8, but for JJA and only showing D - 3 and DO: the surface temperature differences (contour interval is $1 \mathrm{~K}$ ) for (a) $\mathrm{D}-3$ and (b) Do, and (c) precipitable water (contour interval is $2 \mathrm{~kg} \mathrm{~m}^{-2}$ ) for $\mathrm{D}-3$.

tion of the possibility of heavy rainfall is to know when the ingredients for such episodes will make their presence.

It has to be borne in mind that just by looking at a few synoptic-scale fields a definitive forecast of heavy rainfall cannot be issued. The forecasters must look at the mesoscale features of the model output from regional models and also the local terrain characteristics, the discussion of which is beyond the scope of the present study. noteworthy. In summer, most of the differences are not significant. It is believed that such a summary may be used to improve the forecasting ability. It is not intended that meteorologists should use these values directly, but they can be taken as guidance to make decisions about forecast fields obtained from numerical models, because the main problem of accurate predic-

\section{Relation between heavy rainfall and meteorological variables}

In this section, we attempt to gain insights into possible relationships between the meteorological vari- 


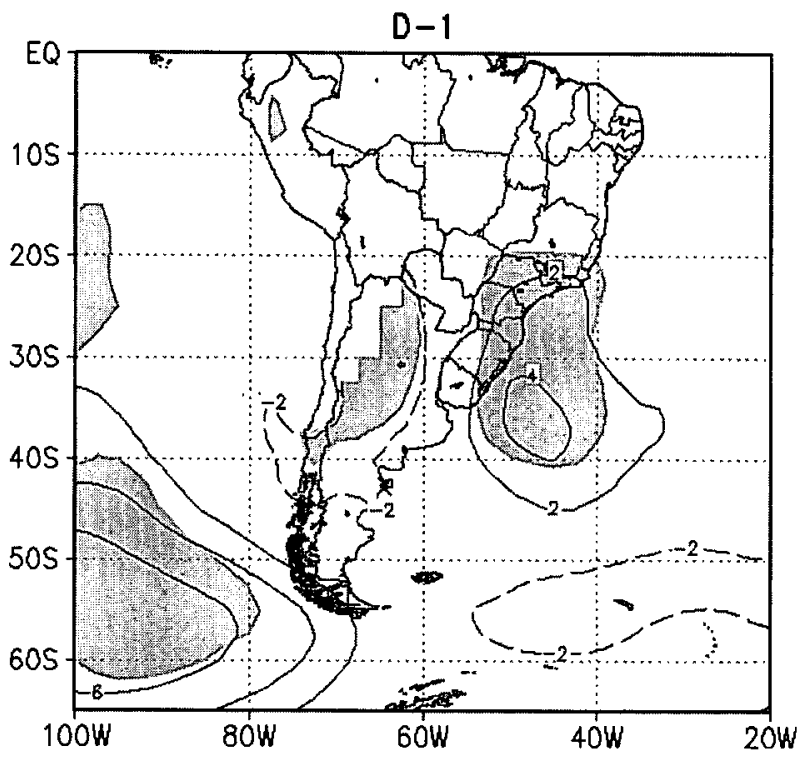

FlG. 13. Same as in Fig. 8, but for the sea level pressure (contour interval is $2 \mathrm{hPa}$ ) on $\mathrm{D}-1$, in $\mathrm{SON}$.

ables and the RQ parameter for the heavy rainfall episodes. Only those variables that show significant correlation are presented here.

Although the autumn season shows the strongest differences for the heavy rainfall episodes, the correlations are not the most significant, except for $\mathrm{D}-1$ and D0 between the $500-\mathrm{hPa}$ geopotential height and RQ. The sequence of lag correlations is shown in Fig. 14. The correlations are significant on D -1 and D0. Examining these fields along with those shown in Fig. 6, it can be said that the negative difference of the geopotential height at the $500-\mathrm{hPa}$ level or the intensity of the trough over western Argentina and Chile is significantly correlated with the rainfall quantity during the heavy rainfall episodes in southern Brazil.
In spring and winter, the atmospheric variables show some significant correlation with RQ only on D0. The thermal advection in winter, however, presents significant correlation prior to D0. According to this field (Fig. 15a), a warm thermal advection in central Argentina on $D-1$ is a signal for a heavy rainfall episode in southern Brazil. On D0, the area of strong correlation moves to Uruguay and adjoining regions (Fig. 15b).

The situation is somewhat different in summer. Some variables show significant lag correlations on $D-2$ and D -1 with heavy rainfall in southern Brazil, especially the meridional wind, mass divergence, and divergence of water vapor flux, all at $850 \mathrm{hPa}$. Some correlation charts are shown in Fig. 16. Although the areas of significant correlations are not large, the correlations are $\geq 0.4$ over Paraguay (Figs. 16a and 16b). These correlations increase in value as well as in areal extent from $\mathrm{D}-2$ to $\mathrm{D}-1$ (figure not shown). This is particularly important because, even though the differences between the heavy and nonheavy episodes are not too high in summer, they are significant for indicating the possibility of occurrence of a heavy rainfall episode.

The opposite is true with the MFC at $700 \mathrm{hPa}$. For this variable significant anomalies are found only in spring. Even then the correlations between this variable and $\mathrm{RQ}$ are not significant. Although the summer anomalies are not significant, the correlation with heavy rainfall is significant (Fig. 16c) over northern Argentina. This suggests that small variations in important variables may results in heavy rainfall in the summer season. A figure for the correlation between RQ and mass convergence is not presented because it is very similar to Fig. 16c.

For the other variables such as precipitable water, lifted index, surface temperature, and 700-hPa mass divergence, no significant relationship with $R Q$ is obtained in any season. These results suggest that these

TABLE 2. Values of meteorological variables and parameters associated with heavy rainfall events $(\mathrm{H})$, and the difference between heavy and nonheavy rainfall composites (D) in southern Brazil on D -1 . Moisture flux convergence $\left(\mathrm{MFC}_{850}, 10^{-7} \mathrm{~s}^{-1}\right)$, thermal advection $\left(\operatorname{Tadv}_{850}, 10^{-4} \mathrm{~K} \mathrm{~s}^{-1}\right)$, and mass divergence $\left(\operatorname{DIV}_{85()}, 10^{-6} \mathrm{~s}^{-1}\right)$ at $850 \mathrm{hPa}$, and the LI $(\mathrm{K})$, surface temperature $\left(T_{\text {slc }}, \mathrm{K}\right)$, surface divergence $\left(\mathrm{DIV}_{\mathrm{sfc}}, 10^{-6} \mathrm{~s}^{-1}\right)$, and $\mathrm{PW}\left(\mathrm{kg} \mathrm{m}^{-2}\right)$ over southern Brazil. The northerly wind component at $850 \mathrm{hPa}\left(v_{850}, \mathrm{~m} \mathrm{~s} \mathrm{~s}^{-1}\right)$ in central South America, the 500-hPa geopotential height $\left(Z_{500}, \mathrm{~m}\right)$ in the trough at latitude $35^{\circ} \mathrm{S}$, and the SLP (hPa) in the low over northern Argentina; N.s. denotes not significant.

\begin{tabular}{|c|c|c|c|c|c|c|c|c|c|c|c|}
\hline Season & & $v_{850}$ & $Z_{500}$ & $\mathrm{MFC}_{850}$ & $\cdot \mathrm{Tadv}_{\mathrm{850}}$ & SLP & LI & $T_{\mathrm{sfc}}$ & $\mathrm{DIV}_{\mathrm{sfc}}$ & $\mathrm{DIV}_{850}$ & PW \\
\hline \multirow[t]{2}{*}{ Autumn } & $\mathrm{H}$ & -12 & 5680 & -1.2 & 0.8 & 1010 & 0 & 295 & -5 & -6 & 35 \\
\hline & $\mathrm{D}$ & -06 & -60 & -0.4 & +0.4 & -4 & -2 & N.s. & -2 & -2 & N.s. \\
\hline \multirow[t]{2}{*}{ Winter } & $\mathrm{H}$ & -12 & 5580 & -0.8 & 1.0 & 1012 & 2 & 290 & -5 & -6 & 30 \\
\hline & $\mathrm{D}$ & -08 & -60 & -0.6 & +0.6 & -6 & -2 & +4 & -6 & -4 & +6 \\
\hline \multirow[t]{2}{*}{ Spring } & $\mathrm{H}$ & -12 & 5600 & -1.2 & 0.8 & 1008 & 0 & 295 & -5 & -9 & 35 \\
\hline & $\mathrm{D}$ & -08 & -60 & -0.6 & +0.8 & -2 & N.s. & N.s. & -2 & -6 & +4 \\
\hline \multirow[t]{2}{*}{ Summer } & $\mathrm{H}$ & -08 & 5750 & -1.0 & 0.3 & 1008 & -2 & 297 & -3 & -6 & 40 \\
\hline & D & -02 & $>-30$ & -0.6 & +0.2 & N.s. & N.s. & N.s. & N.s. & N.s. & N.s. \\
\hline
\end{tabular}



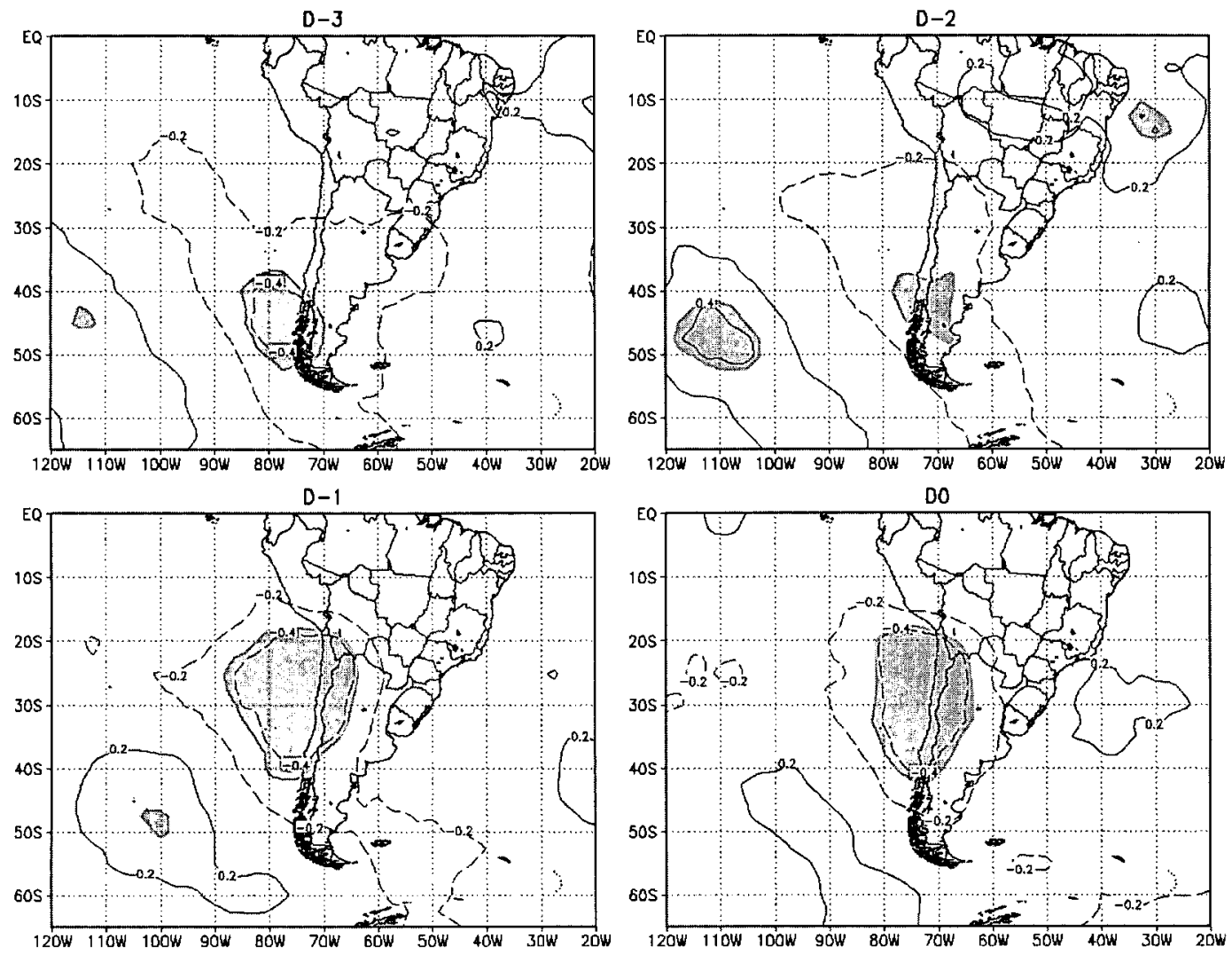

FIG. 14. Rank correlation coefficient between 500-hPa geopotential height anomaly and RQ for the 41 autumn episodes. Contour interval is 0.2 . D $-d$ indicates the $d$ th day prior to the heavy rainfall occurrence. Shaded areas are significant at $95 \%$ level.

variables and parameters are not good indicators for heavy rainfall occurrence in southern Brazil. Konrad (1997) found, the for summer season in the southeastern United States, that even though large values of moisture and instability parameters are common in heavy rainfall episodes, their magnitude did not discriminate the heaviest ones from the nonheavy ones. This appears to apply in southern Brazil too, in summer.

One of the great problems of the rainfall forecast (heavy or not) is the accurate prediction of the time and

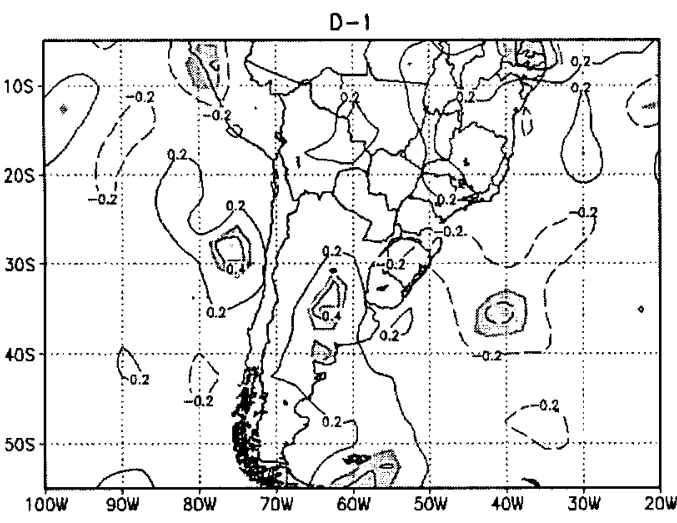

(a)

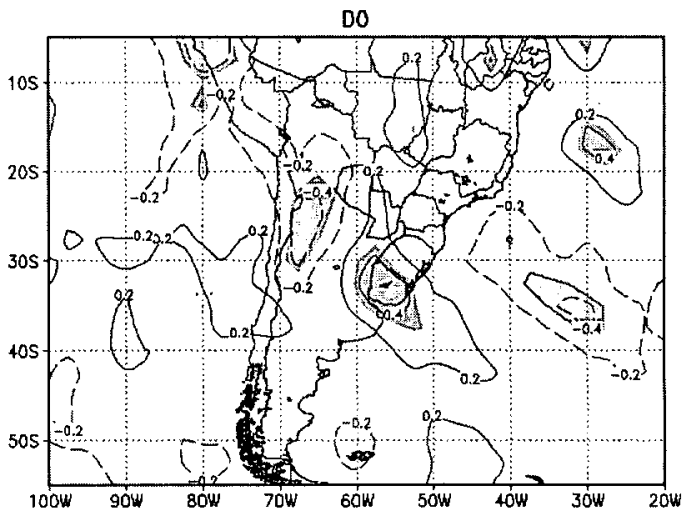

(b)

FIG. 15. Same as in Fig. 14, but for 850-hPa thermal advection in JJA on (a) D - 1 and (b) D0. 


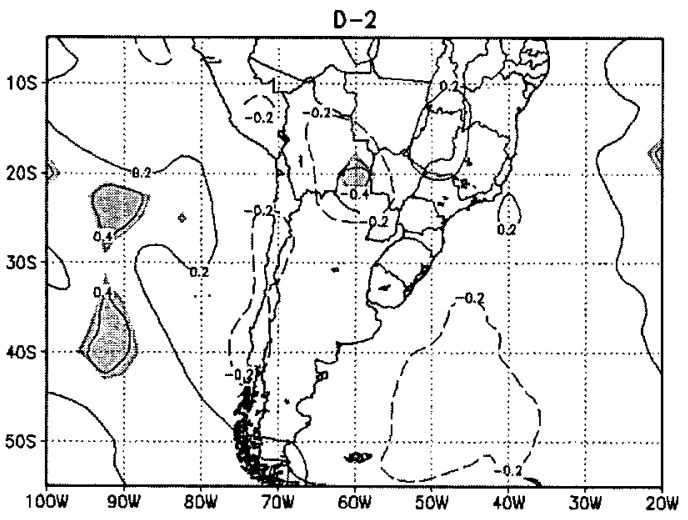

(a)

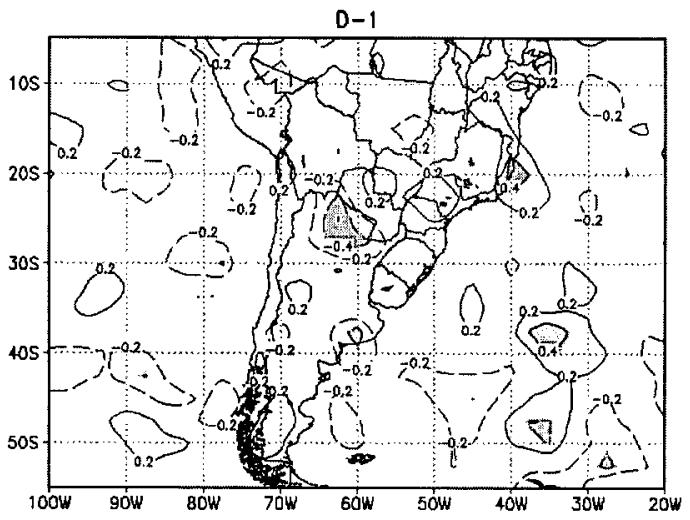

(c)

location of the CI. Banacos and Schultz (2005) emphasized that the CI forecast based on surface MFC is not good for this purpose because of factors like large-scale midlevel subsidence and mass convergence above planetary boundary layer, which can confuse the meteorologist about the CI condition. They recommend the use of mass convergence instead of surface MFC.

The practice of using surface MFC became popular in countries that have a dense observation network, as in the United States. In Brazil, the observation network is far from dense (almost $80 \%$ of the stations in Fig. 1 only report rain). Therefore, mass divergence is investigated at other levels in addition to the surface level. At the surface and $700 \mathrm{hPa}$, mass divergence does not show significant correlation with $\mathrm{RQ}$ in the days prior to the heavy rainfall episodes. At $850 \mathrm{hPa}$, mass divergence presented differences and correlation values similar to the MFC, showing that both variables are suitable for consideration in heavy rainfall forecasting.

Moreover, according to the schematic diagram in Fig. 2 of Banacos and Schultz (2005), mass convergence at any level in the lower troposphere can cause CI. An evaluation of the convergence at several levels over

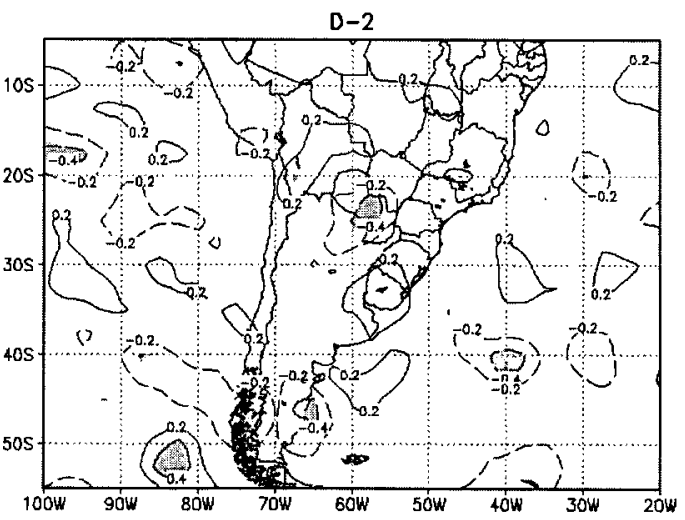

(b)
FIG. 16. Same as in Fig. 14, but for (a) 850 -hPa meridional wind component on D - 2, (b) 850-hPa MFC on D - 2, and (c) 700-hPa MFC on D - 1 in DJF. The lags are shown at the top of each panel. southern Brazil may prevent the forecaster from misjudging the atmospheric condition. Thus, it is necessary to evaluate the mass convergence at as many levels as possible in the lower troposphere when a heavy precipitation situation is suspected.

\section{Extreme episodes}

To appreciate the distinguishing characteristics of the most intense heavy rainfall episodes (extreme episodes), composites of the $10 \%$ of the episodes (17) that presented the largest $100 \mathrm{~mm} \mathrm{day}{ }^{-1}$ isohyet area (A100) are discussed. The composites of the extreme episodes are expected to highlight the synoptic wave and the attendant flow characteristics. The results of the last section show that there are many common features in all seasons and that a composite of all the extreme episodes, irrespective of the season, may show the predominant features of the situation, which can be used as a prototype for operational work. Composites of 17 episodes are considered fairly robust as compared to very few cases in any given season.

On D0 the composites show that warm advection at 


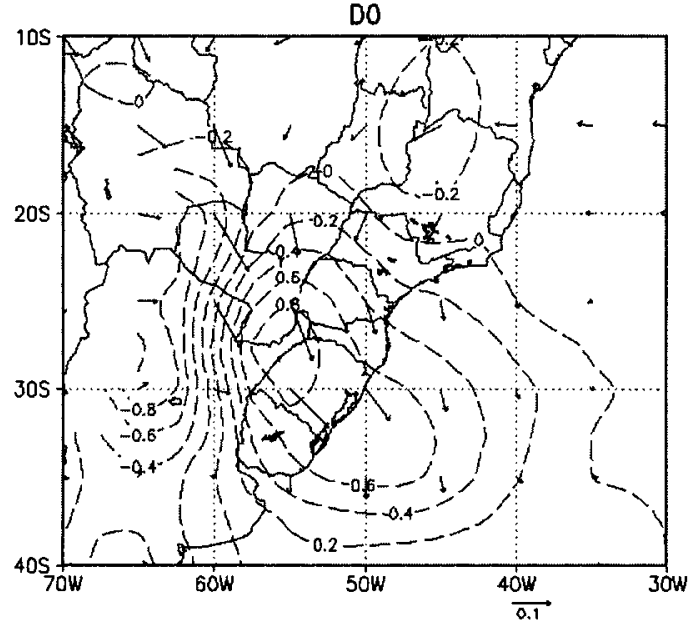

(a)

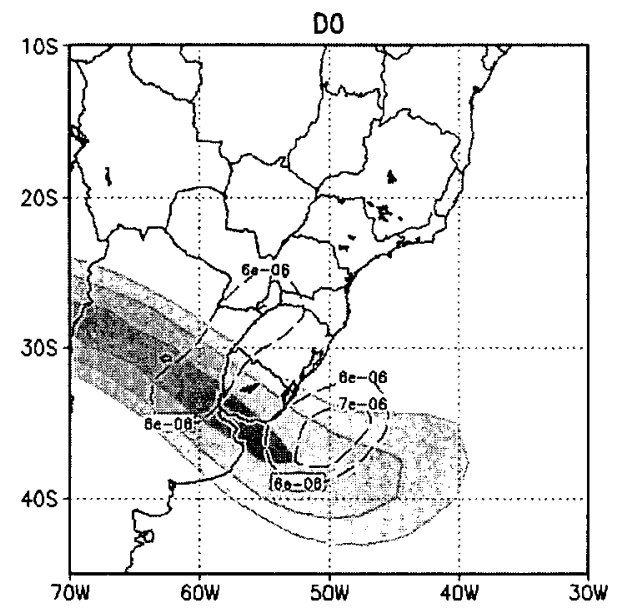

(c)

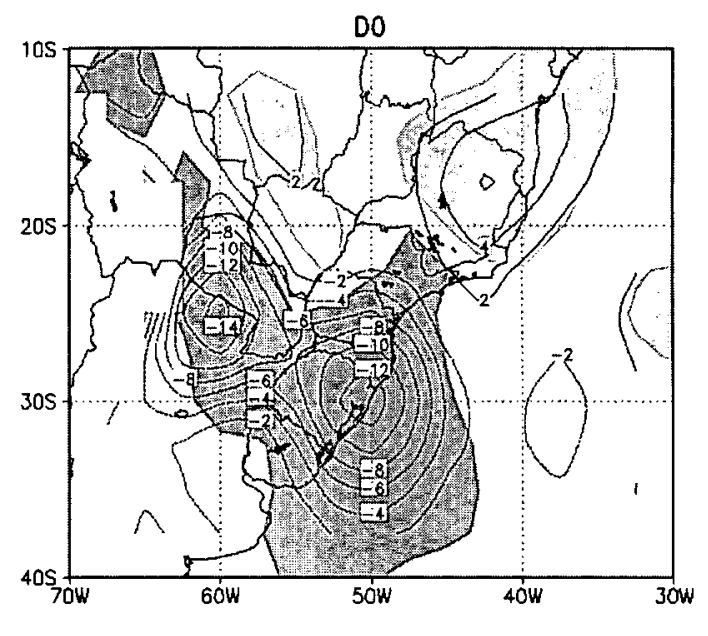

(b)

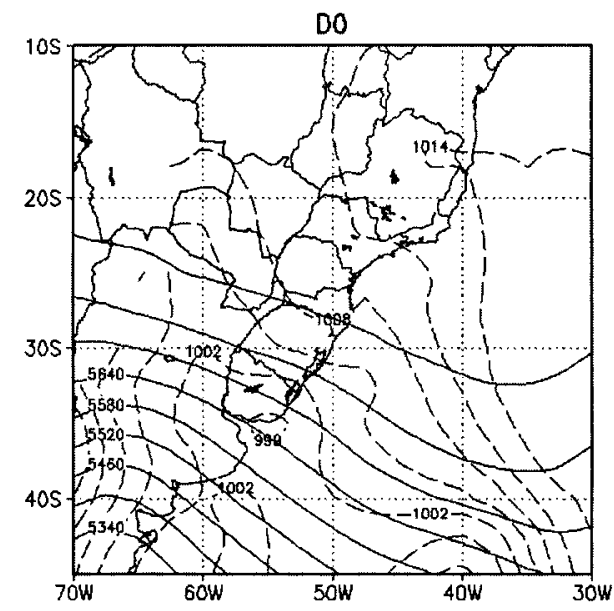

(d)

FIG. 17. Composites for 17 extreme rainfall episodes on D0. (a) 850 -hPa moisture transport (vectors, $10^{-2} \mathrm{~kg} \mathrm{~m}$ $\mathrm{kg}^{-1} \mathrm{~s}^{-1}$ ) and thermal advection (dashed contours at intervals of $0.2 \times 10^{-4} \mathrm{~K} \mathrm{~s}^{-1}$ ); (b) 850 -hPa MFC (dark shaded area represents convergence values $\leq-0.2 \times 10^{-7} \mathrm{~s}^{-1}$ and light shaded area represents divergence values $\geq 0.2 \times$ $10^{-7} \mathrm{~s}^{-1}$ ) and mass divergence (contour interval is $2 \times 10^{-6} \mathrm{~s}^{-1}$ ); (c) 250 -hPa isotachs (shaded values $\geq 33 \mathrm{~m} \mathrm{~s}^{-1}$, contour interval of $3 \mathrm{~m} \mathrm{~s}^{-1}$ ) and divergence (dashed contours $\geq 5 \times 10^{-6} \mathrm{~s}^{-1}$ with contour interval of $1 \times 10^{-6} \mathrm{~s}^{-1}$ ); and (d) 500-hPa geopotential height (continuous line with contour interval of $60 \mathrm{~m}$ ) and sea level pressure (dashed line with contour interval of $3 \mathrm{hPa}$ ).

$850 \mathrm{hPa}$ is very dominant over southern Brazil and surrounding areas (Fig. 17a). It is nearly $6 \mathrm{~K} \mathrm{day}^{-1}$. The moisture transport also is very dominant over Paraguay and southern Brazil (Fig. 17b). The MFC in the south and moisture flux divergence over northeastern Brazil are prominent. The moisture divergence over the northeastern coast of Brazil suggests that, in addition to the southern Amazon region from which the low-level jet east of the Andes transports moisture and sensible heat to south, the western tropical South Atlantic also is a moisture source region. Often, meteorologists attribute the MFC related with rainfall in southern Brazil to the low-level jet from Amazon region, but the divergence over eastern Brazil is noteworthy (Fig. 17b). As shown in the previous sections, the 850 -hPa mass divergence presents a similar importance (magnitude and position) for heavy rainfall occurrence as compared with $850-\mathrm{hPa} \mathrm{MFC}$, showing that both variables are suitable for heavy rainfall indication.

Figure $17 \mathrm{c}$ shows that almost the entire southern Brazil region is under intense upper-level divergence, especially on the equatorward side of the jet core, that is, the anticyclone side. Strong convergence in the lower troposphere and strong divergence in the upper tropo- 


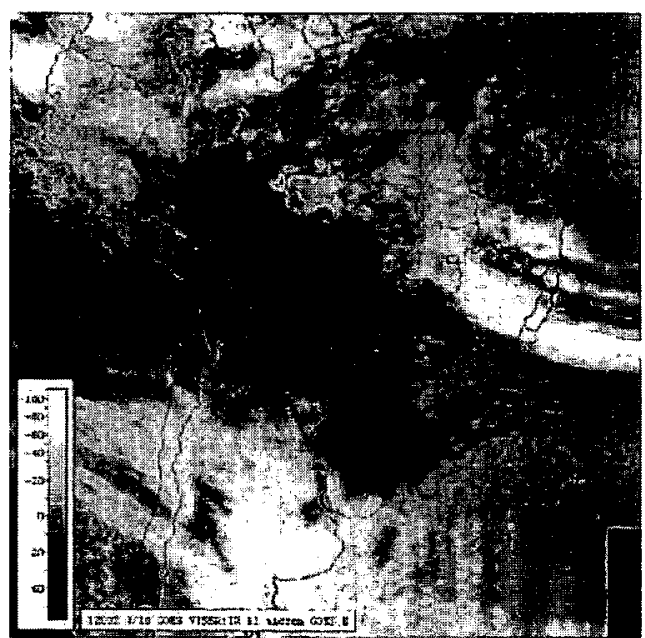

(a)

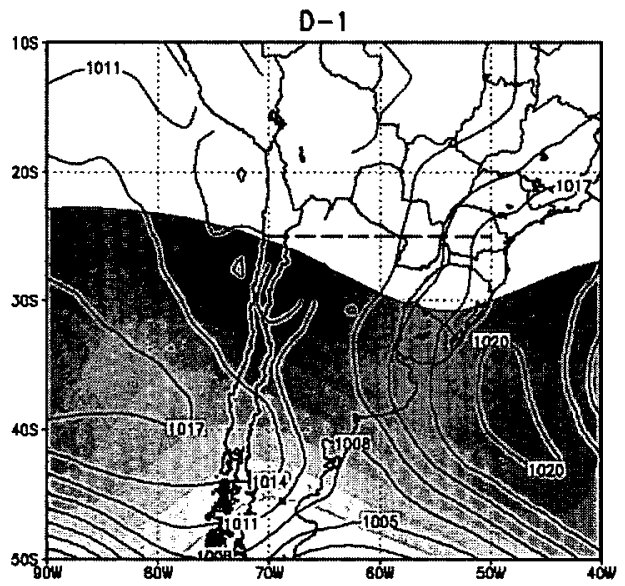

(c)

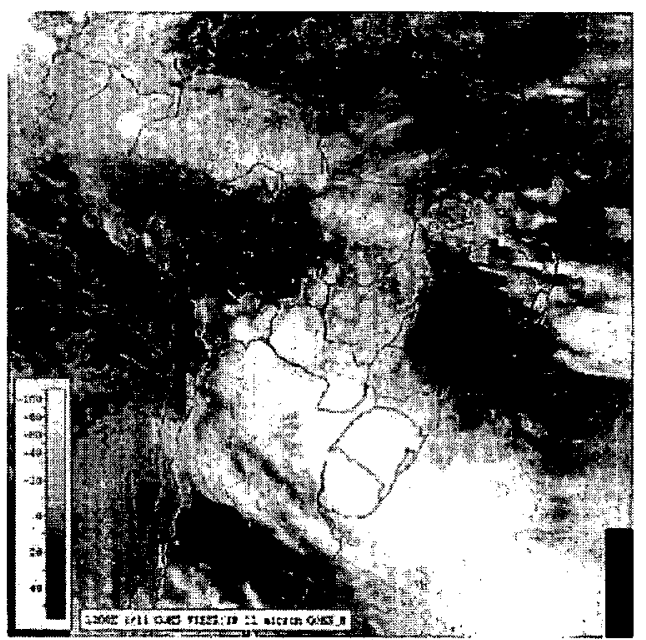

(b)

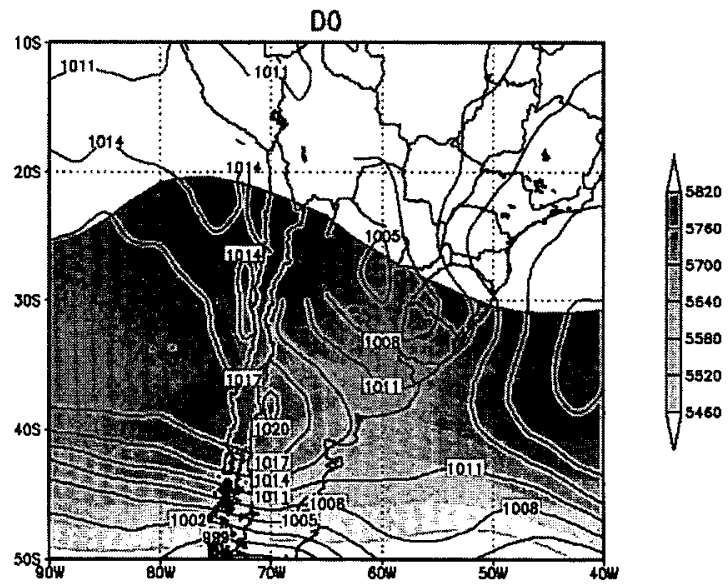

(d)

FIG. 18. IR satellite imagery and surface and 500-hPa analyses for the heavy rainfall case on 11 and 12 Apr 1992 . Images for (a) 1200 UTC 10 Apr 1992 (day D - 1) and (b) 1200 UTC 11 Apr 1992 (day D0), and geopotential height at $500 \mathrm{hPa}$ (shaded) and sea level pressure (contours) for days (c) D - 1 and (d) D0. The dashed line along $22.5^{\circ} \mathrm{S}$ in (c) is used for the vertical section shown in Fig. 19c.

sphere support the strong regional-scale vertical motion necessary for sustained intense convective activity.

The presence of a deep surface trough over eastern Argentina and a midtropospheric trough in western Argentina show the baroclinic nature of the synoptic system (Fig. 17d). The warm advection and the moisture transport take place mainly east of the surface trough.

\section{Case study}

The fields shown in the previous sections are averages of a number of cases. Although these fields present common characteristics that distinguish the heavy rainfall episodes from nonheavy ones, they do not show how intense the fields in an individual episode are. Thus, in this section an episode that has the largest rainfall amounts in southern Brazil in the 11-yr period studied is presented. It occurred between 11 and 12 April 1992 (Fig. 2).

The IR satellite images in Figs. 18a and 18b show the approach of a frontal cloud band and the intensification of the convective activity in southern Brazil. The formation of a low pressure area in northern Argentina along with the intensification of a midtropospheric trough (Figs. 18c and 18d) are the dominant features. The entirety of southern Brazil, with convective activity and rainfall, is under the influence of the frontal system (Fig. 18b) on 11 April. The trough over southern Chile on 10 April deepens and moves on to central Argentina on 11 April. The cyclonic vorticity advection helps the 


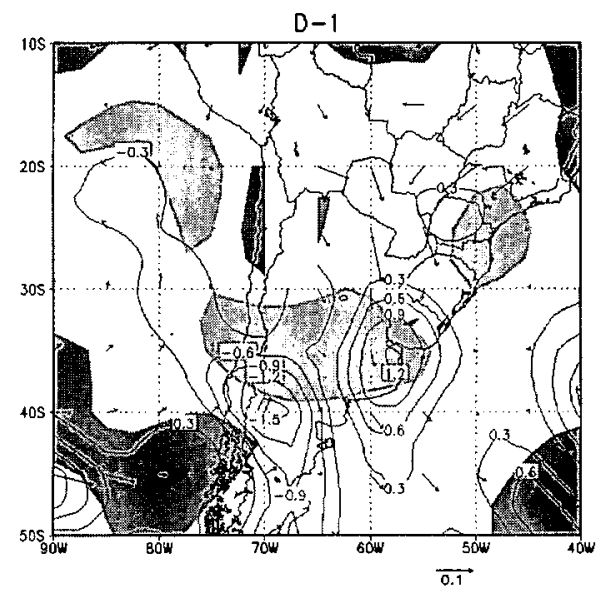

(a)

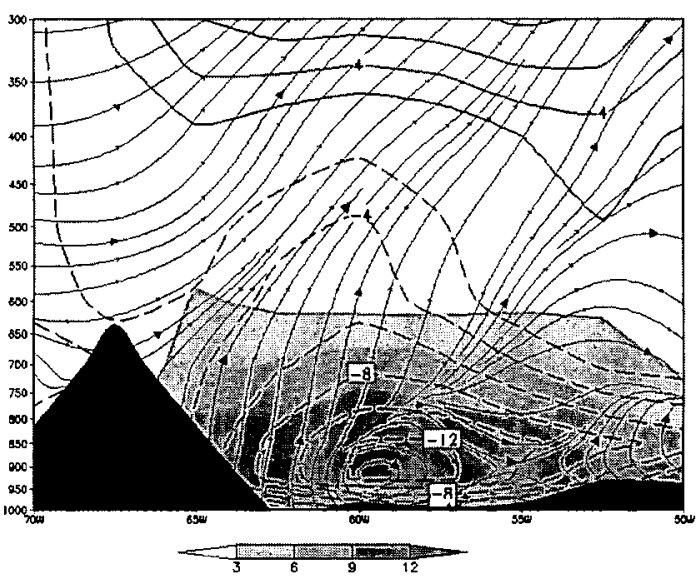

(c)

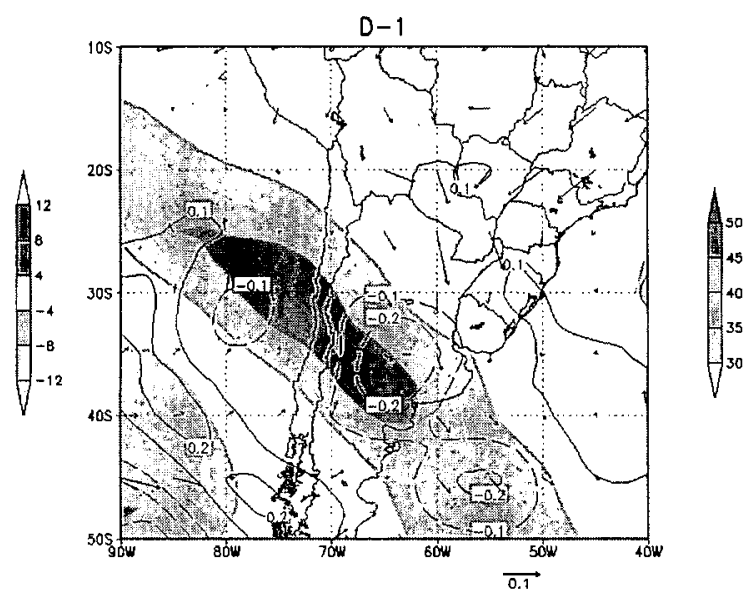

(b)

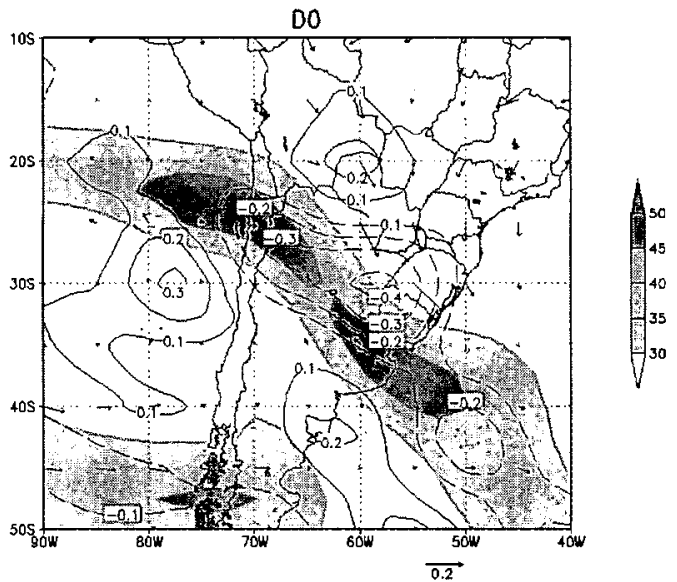

(d)

FIG. 19. (a) Moisture flux convergence (shaded, $10^{-7} \mathrm{~s}^{-1}$ ), moisture transport (vectors, $10^{-2} \mathrm{~kg} \mathrm{~m} \mathrm{~kg}^{-1} \mathrm{~s}^{-1}$ ), and thermal advection (contours, $10^{-4} \mathrm{~K} \mathrm{~s}^{-1}$ ) at $850 \mathrm{hPa}$; (b) wind magnitude (shaded, $\mathrm{m} \mathrm{s}^{-1}$ ) at $250 \mathrm{hPa}$, omega (contours, $\mathrm{Pa} \mathrm{s}^{-1}$ ) at $500 \mathrm{hPa}$, and moisture transport $\left(10^{-2} \mathrm{~kg} \mathrm{~m} \mathrm{~kg}^{-1} \mathrm{~s}^{-1}\right.$ ) at $850 \mathrm{hPa}$; (c) vertical profile of specific humidity (shaded, $\mathrm{g} \mathrm{kg}^{-1}$ ), streamlines, and meridional wind (contours, $\mathrm{m} \mathrm{s}^{-1}$ ) at $25^{\circ} \mathrm{S}$ (dashed line drawn in Fig. $18 \mathrm{c}$ ) for D - 1. (10 Apr 1992); topography is shown in dark shading. (d) Wind magnitude (shaded, $\mathrm{m} \mathrm{s}^{-1}$ ) at 250 $\mathrm{hPa}$, omega (contours, $\mathrm{Pa} \mathrm{s}^{-1}$ ) at $500 \mathrm{hPa}$, and moisture transport $\left(10^{-2} \mathrm{~kg} \mathrm{~m} \mathrm{~kg}^{-1} \mathrm{~s}^{-1}\right)$ at $850 \mathrm{hPa}$.

surface development in northern Argentina. The eastwest pressure gradient accelerates the northerlies, which transport moisture and heat into southern Brazil. The case presented is in conformity with the composite picture (Fig. 17d).

Some more details of this case can be seen in Fig. 19. On $\mathbf{D}-1$ the strong moisture transport from the northnorthwest and northeast cause strong MFC and warm advection southwest of southern Brazil (Fig. 19a). This low-level feature, along with the middle- and upperlevel conditions southwest of southern Brazil (Fig. 19b), helps the intensification of the surface low over northern Argentina observed in Fig. 18d. To see how intense and deep the moisture transport in this heavy rainfall episode is, Fig. 19c presents a vertical section of mois- ture, meridional wind, and vertical circulation along $25^{\circ} \mathrm{S}$ (dashed line in Fig. 18c). There is a deep, moist layer that extends from surface up to about $650 \mathrm{hPa}$ (>3 $\mathrm{g} \mathrm{kg}^{-1}$ ) and an even deeper northerly wind layer, from the surface up to the middle troposphere. These northerly winds and high-moisture content, along with the increase of upward movement (Figs. 19b and 19d), act to destabilize the middle-lower troposphere, and the accompanying strong vertical transport of moisture causes the large 24-h-accumulated rainfall shown in Fig. 2. The superimposition of Figs. 2 and 19d shows that heavy rainfall occurs on the equatorward side of the upper-level jet core. The circulation east of the jet is anticyclonic, which provides upper-level divergence over southern Brazil. 


\section{Conclusions}

One of the purposes of this study is to provide to the operational meteorologist with some forerunning synoptic-scale features of the heavy rainfall episodes in southern Brazil. So, the mean features associated with 170 heavy rainfall episodes in southern Brazil that are distinct from the nonheavy rainfall episodes are presented. The definition of heavy rainfall may not be taking into account all of the factors that make a rainfall episode a heavy one, but it considers the most important aspects of precipitation-the areal extent and the intensity - that can be inferred from surface observations.

Based in the composites for up to 3 days prior to the heavy rainfall episodes, the results show how different these episodes are in comparison with nonheavy rainfall episodes. Some common features observed in all seasons are (a) a deepening middle-level trough moving to central Argentina, (b) the formation of a surface thermal low pressure center in northern Argentina, and (c) a northerly low-level jet intensification over Paraguay and neighboring regions that brings warm, moist air into southern Brazil. These features are not entirely new, but the present study shows the magnitudes of the features and the differences between heavy rainfall episodes and nonheavy rainfall episodes, bringing some new information about this subject.

Moreover, other important findings must be emphasized in order to help the meteorologists to prepare a strategy for heavy rainfall forecasting in southern Brazil:

- The low-level jet east of Andes is often taken as the most important source of moisture (Saulo et al. 2004; Marengo et al. 2004, e.g.), but the results obtained here show that it may not be the only one. A strong moisture divergence area is observed over eastern Brazil and the adjoining South Atlantic during heavy rainfall episodes in southern Brazil.

- Sea level pressure is not a good indicator for heavy rainfall occurrence in southern Brazil. This variable does not show any significant relationship with heavy rainfall in any season and, therefore, its use is not recommended for heavy rainfall forecast in southern Brazil.

- As observed by Konrad (1997), instability indexes and precipitable water do not show any anticipated indication of the possibility of heavy rainfall. They become significant only on D0. Thus, although in many forecast centers of Brazil meteorologists give more attention to the instability indexes (M. E. Seluchi 2006, personal communication), their use in fore- casting heavy rainfall in southern Brazil is not recommended.

- The mass convergence and/or MFC should be inspected at as many levels as possible in the lower troposphere in order to avoid misjudging the possibility of heavy rainfall occurrence.

- In spring and in summer, the MFC at $700 \mathrm{hPa}$ is a significant feature associated with heavy rainfall. Thus, its inspection can help the detection of possibility of heavy rainfall occurrence.

- In winter, the most important variable for indication of heavy rainfall is warm advection, because it shows the greatest relationship with heavy rainfall episodes in this season.

It can be seen that a limited set of variables and parameters can be used to provide useful information about the possibility of heavy rainfall episodes in southern Brazil. However, as already mentioned in the previous sections, the forecast of heavy rainfall (and even of the nonheavy rainfall) is not trivial. The results emphasize this problem, by not presenting exactly the same pattern of composites for all seasons. Each season has its particularities and the forecasters should know them. Especially, the summer season appears to have the subtlest differences between heavy and nonheavy rainfall episodes, making the forecast task still more difficult. Junker et al. (1999) also found some factors (as those discussed by Doswell et al. 1996) that make a difference for the occurrence of a heavy rainfall episode in the summer in the United States, and the differences were also small. Based on this, they affirmed that no single variable and parameter can be used for heavy rainfall prediction, and therefore a set of variables must be used to detect the possibility for such episodes. It should also be mentioned that there are some cases of heavy rainfall where the synoptic situation does not correspond to the composites. Such outliers are few and were observed in nonwinter seasons. This increases the difficulty in forecasting the heavy rainfall situation.

It is also important to emphasize that the present study uses data with grid spacing that cannot resolve smaller-scale features such as mesoscale convective systems (MCS), squall lines, and cold and warm fronts. Thus, the results presented here show the large-scale conditions that can favor heavy rainfall occurrence. The forecasters must bear in mind that along with the conditions presented here, mesoscale forecast information from limited-area models must be consulted.

By showing the distinct synoptic-scale conditions associated with the heavy rainfall in southern Brazil and the magnitudes of the parameters and variables (Table 2) that present a significant relationship with heavy 
rainfall, the authors expect that the forecasters may gain improved reliability in forecasts of such episodes in southern Brazil. The findings of the present study may not be sufficient to forecast the exact quantity and location of heavy rainfall episodes, but strategies for such quantitative prediction can be worked out only after knowing the differences that can make a rain event into a heavy rainfall episode.

Acknowledgments. The first author was supported by the Conselho Nacional de Desenvolvimento Científico e Tecnológico (CNPQ; National Council of Scientific and Technological Development), Brazil, through the Fundo Setorial para Hidrologia (CT-Hidro, Sectorial Fund for Hydrology). The authors thank the anonymous reviewers who have contributed to the improvement of the manuscript.

\section{REFERENCES}

Banacos, P. C., and D. M. Schultz, 2005: The use of moisture flux convergence in forecasting convective initiation: Historical and operational perspectives. Wea. Forecasting, 20, 351-366.

Bonatti, J. P., and V. B. Rao, 1987: Moist baroclinic instability in the development of North Pacific and South American intermediate-scale disturbances. $J$. Atmos. Sci. 44, 2657-2667.

Carvalho, L. M. V., C. Jones, and B. Leibmann, 2002: Extreme precipitation events in southeastern South America and large-scale convective patterns in the South Atlantic convergence zone. J. Climate, 15, 2377-2394.

Doswell, C. A., III, H. E. Brooks, and R. A. Maddox, 1996: Flash flood forecasting: An ingredients-based methodology. Wea. Forecasting, 11, 560-581.

Harnack, R. P., K. Apffel, and J. R. Cermack, 1999: Heavy precipitation events in New Jersey: attendant upper air conditions. Wea. Forecasting, 14, 933-954.

Junker, N. W., R. S. Schneider, and S. L. Fauver, 1999: A study of heavy rainfall events during the great Midwest flood of 1993. Wea. Forecasting, 14, 701-712.
Kalnay, E., and Coauthors, 1996: The NCEP/NCAR 40-Year Reanalysis Project. Bull. Amer. Meteor. Soc., 77, 437-471.

Konrad, C. E., II, 1997: Synoptic-scale features associated with warm season heavy rainfall over the interior southern United States. Wea. Forecasting, 12, 557-571.

Kousky, V. E., and I. F. A. Cavalcanti, 1984: Eventos Oscilação Sul-El Niño: Características, evolução e anomalias de precipitação (in Portuguese). Cienc. Cult., 36, 1888-1889.

Marengo, J. A., W. R. Soares, M. Nicolini, and C. Saulo, 2004: Climatology of low-level jet east of the Andes as derived from the NCEP-NCAR reanalyses: Characteristics and temporal variability. J. Climate, 17, 2261-2280.

Ramírez, M. C. V., N. J. Ferreira, and M. A. Gan, 2000: Vórtices ciclônicos desprendidos em altos níveis que se originam no leste do Pacífico Tropical Sul. Parte 1: Aspectos sinóticos relacionados a sua formação (Upper level cut-off vortices generated in the eastern tropical South Pacific. Part 1: Synoptic features related with their formation). Preprints, $X I$ Brazilian Meteorology Congress, Rio de Janeiro, Brazil, Brazilian Meteorological Society, 3287-3295.

Rao, V. B., and K. Hada, 1990: Characteristics of rainfall over Brazil: Annual variations and connections with the southern oscillation. Theor. Appl. Climatol., 42, 81-91.

Satyamurty, P., C. A. Nobre, and P. L. Silva Dias, 1998: Tropies: South America. Meteorology of the Southern Hemisphere, Meteor. Monogr., No. 40. Amer. Meteor. Soc., 119-139.

Saulo, A. C., M. E. Seluchi, and M. Nicolini, 2004: A case study of a Chaco low-level jet event. Mon. Wea. Rev., 132, 2669-2683.

Uccellini, L. W., and D. R. Johnson, 1979: The coupling of upper and lower tropospheric jet streaks and implications for the development of severe convective storms. Mon. Wea. Rev., 107, 682-703.

Velasco, I., and J. M. Fritsch, 1987: Mesoscale convective complexes in the Americas. I. Geophys. Res., 92, 9591-9613.

Wilks, D. S., 1995: Statistical Methods in the Atmospheric Sciences: An Introduction. Academic Press, 470 pp.

Zhu, Y., and Z. Thot, 2001: Extreme weather events and their probabilistic prediction by the NCEP ensemble forecast system. Preprints, Symp. on Precipitation Extremes: Prediction, Impacts, and Responses, Albuquerque, NM, Amer. Meteor. Soc., CD-ROM, P1.38. 


\section{Wilson Web}

\section{COPYRIGHT INFORMATION}

TITLE: Dynamical and Synoptic Characteristics of Heavy Rainfall Episodes in Southern Brazil

SOURCE: Mon Weather Rev 135 no2 F 2007

The magazine publisher is the copyright holder of this article and it is reproduced with permission. Further reproduction of this article in violation of the copyright is prohibited. To contact the publisher:

http://www.ametsoc.org/AMS/ 